\title{
ASPECTOS FOLKLÓRICOS EN CUENTOS DE MI TÍA PANCHITA*
}

Odilie Cantillano

Universidad de Arizona

Estas líneas tienen por objeto demostrar el carácter internacional de la trama de los relatos que forman la colección de Cuentos de mi tía Panchita de Carmen Lyra y determinar su relación con la tradición hispánica y su posible entronque con la tradición oral o literaria, para luego fijar, hasta donde sea posible, la fisionomía propia de la versión de esta autora.

Siguiendo el procedimiento usado por los folkloristas, se determinará el "cuento-tipo"1 al que pertenece cada uno de acuerdo con los índices internacionales de Aäme-Thompson, Boggs y Hansen ${ }^{2}$. Se

* Capítulo de la disertación Carmen Lyra y los Cuentos de mi tía Panchita. Aspectos folklóricos, literarios y lingüísticos, presentada como requisito parcial para optar al Doctorado en Filosofía con especialización en Español en el Colegio de Graduados de la Universidad de Arizona, Departamento de Lenguas Romances, 1972.

1. El término "cuento-tipo" es usado por Susana Chertudi, Cuentos folklóricos de la Argentina, primera serie (Buenos Aires: Instituto Nacional de Filología y Folklore, 1960) (11). Ese mismo se usará en este trabajo cada vez que se quiera indicar lo que en inglés se denomina "tale type". Según la definición de Stith Thompson, "el cuento-tipo es un cuento tradicional que tiene vida propia. Puede cerrarse independientemente, ya que su sentido no depende de otro cuento, pero puede aparecer en conjunción con otro y consistir en uno o más motivos ("motifs"). El motivo es el elemento más pequeño de un cuento con la suficiente calidad para persistir en la tradición. Para lograrlo debe haber en él algo notable o poco común", Stith Thompson, The Folktale (New York: Dryden, 1946) 216.

2. Antti Aäme y Stith Thompson, Types of the Folktale. A Classification and Bibliography (Helsinki: F.F. Communications, 90, n. 184, 1961); Ralph Steele Boggs, Index of the Spanish Folktales (Helsinki: F.F. Communications, 60, 1930); Terence Leslie Hansen, Types of the 
reseñará también la trama del cuento tipo, según esos índices para compararla con la del cuento que concierne, indicando los elementos coincidentes para relacionarlos luego con los de las versiones consultadas en cada caso. Después se señalarán aspectos en que cada cuento de la Tía Panchita se distingue de los demás.

\section{Los cuentos de hadas}

Para Stith Thompson, uno de los conceptos con que se tropieza más a menudo el estudioso al examinar los cuentos folklóricos es el que los alemanes llaman "Märchen", para el cual el inglés no tiene equivalente satisfactorio, aunque se acostumbra traducirlo como "Fairy tale" (cuento de hadas) o "household tale" 3 . Thompson se opone a estos términos, pues en la mayoría de los cuentos no aparecen "hadas", y "household" resulta demasiado general. Define "Märchen" como:

A tale of length involving a succession of motifs or episodes. It moves in an unreal world without definite locality or definite characters and is filled with the marvelous. In this never-never land humble heroes kill adversaries, succeed to kingdoms and marry princesses ${ }^{4}$.

Pese a la objeción mencionada, se usará aquí el término "cuentos de hadas", ya que es el más común en español. Pertenecen a esta categoría «Juan el de la carguita de leña», «El Cotonudo», «La mica», «El pájaro dulce encanto» y «La negra y la rubia», pues en ellos los

Folksale in Cuba, Puerto Rico, The Dominican Republic and Spanish America (Berkeley and Los Angeles: University of California Press, 1957).

3. Los folkloristas George Boswell y Russell Reaver, Fundamentals of Folk Literature (Osterhug: Anthropological Publications, 1962) 116, dicen refiriéndose a este tipo de cuento que son fáciles de reconocer pero difíciles de definir. Richard M. Dorson, «Foreword,» Yolando Pino Saavedra, ed., Folkıales of Chile (Chicago: University of Chicago Press, 1967) ix, define "Märchen" como: "Wonder tales filled with magical and violent adventures of low-bom heroes winning princesses and vanquishing ogroes."

4. Thompson, The Folktale, 7-8. Veánse también 386 y 387. 
héroes y las heroínas obtienen la mano de princesas y príncipes, y hasta riquezas. Además, abunda lo maravilloso: una flauta de caña delata un fratricidio, la muerte personificada participa en la acción de «Uvieta» y el diablo es un persona je importante, como también lo es en «La suegra del Diablo»; Dios y la Virgen son agentes del feliz desenlace de «Uvieta», «Juan el de la carguita de leña», «Escomponte perinola», «La negra y la rubia», «La casita de las torrejas», así como las brujas lo son en «Salir con un domingo siete» y el alma de un muerto agradecido en «El pájaro dulce encanto».

En estos cuentos juegan un papel importante los objetos mágicos como una varita de virtud, una flor que devuelve la vista, una perinola que da golpes, una arquita que provee lujosos trajes y una muñequita que habla y un pá jaro que también habla y un caballo que vuela. Sólo en «El tonto de las adivinanzas» el héroe gana la mano de la princesa gracias a su sagacidad.

«La negra y la rubia» ${ }^{5}$

Este cuento pertenece al llamado «Ciclo de la Cenicienta», del cual ya en 1892 se conocían 345 versiones ${ }^{6}$. Es decir, constituye una versión del conocido cuento de «La Cenicienta».

En Types of the Folktale de Antti Aäme y Stith Thompson, índice cuyo énfasis está en los cuentos del Vie jo Mundo, se clasifica el de «La Cenicienta» bajo el cuento-tipo 510. La versión de Carmen Lyra concuerda con el 510 en los siguientes elementos:

5. Carmen Lyra, Cuentos de mi tía Panchita (cuarta edición: San José: Editora Las Américas, 1956) 118,128 . Todas las citas pertenecen a esta edición, que en realidad es una reimpresión de la tercera (1926). Estos cuentos empezaron a publicarse separadamente en la revista Lecturas el 30 de setiembre de 1918. Se hicieron luego tres ediciones: 1920, por Joaquín García Monge, Imprenta Alsina; 1922, edición El Convivio; 1926, Imprenta María V. de Lines.

6. Marian Roalfe Cox, Cinderella: Three Hundred and Forty-Five Variants of Cinderella, Catskin and Cap $O$ ' Rushes, Abstracted and Tabulated with a Discussion of Medieval Analogues and Notes (London: Publications of the Folklore Society, 31, 1892.) 
I The Persecuted Heroine. a) The heroine is abused by her stepmother and stepsister(s).

II The Magic Help. c) While she is acting as servant she is advised by a supernatural being.

III Meeting the Prince. c) She is seen in her beautiful clothing in the church. Threefold visit to church. [Este último elemento pertenece al cuento-tipo $510 \mathrm{~A}$ ].

IV Proof of Identity.

V Marriage with the Prince.

«La negra y la rubia» presenta sus elementos de la forma siguiente:

1. Un viudo ambicioso se casa con una viuda creyendo que tiene dinero. Esta tiene una hija negra y aquel una blanca.

2. La blanca es relegada a la cocina.

3. La rubia encuentra en el jardín una muñequita que resulta ser la Virgen.

4. El padre, comerciante, va a hacer un viaje y les pregunta a ambas hijas lo que desean que les traiga a su regreso.

5. La Virgen aconseja a la rubia que pida una arquita.

6. Tres veces la Virgen manda a la rubia a misa para lo cual aparece un suntuoso vestido cada vez en el arca.

7. El príncipe la ve en la iglesia y se enamora de ella.

8. Tres veces la ve la negra sin reconocerla y trata de intimar con ella.

9. Después de ser burlado dos veces, el príncipe logra localizar la casa y se pasea frente a ella.

10. La negra cree que la corteja a ella, pero por prevención, mete a la rubia debajo de una gran olla. Una lora revela el escondite con la cantilena: "La niña la linda debajo de una olla/la negra feroza [sic] se quiere casar" (126).

11. El príncipe le propone matrimonio. La rubia acepta después de consultar con la muñequita, es decir, la Virgen. Esta le aconseja 
aceptarlo pero le advierte que no debe levantar los ojos del suelo hasta que el sacerdote no les haya dado la bendición.

12. La rubia obedece estrictamente el mandato aunque el príncipe le pide que lo mire.

13. Un ángel trae un lujoso vestido en la arquita.

14. La Virgen baja del cielo para ser la madrina.

15. La rubia logra que un palaciego se case con la negra. No lo hace muy feliz.

16. El príncipe y la rubia sílo son. A su muerte vanal cielo, donde cantan alabanzas a la Virgen.

Al confrontar los elementos de «La negra y la rubia» con los del cuento-tipo, se nota que concuerdan aproximadamente en cuanto al elemento I. Con respecto al elemento II, la Virgen como agente sobrenatural no aparece en Aärne-Thompson, sí en el índice de Hansen: $510 \mathrm{IIc}$, «Virgen» $\mathrm{y}$ *h «The Virgin gives her a magic wand.» La muñeca y el arca hacen las veces de varita mágica en el cuento de Carmen Lyra.

También existen semejanzas con el punto III (Aäme-Thompson). La rubia asiste a la iglesia tres veces, ahí el príncipe la ve y se enamora de ella. Así pues, la iglesia es el punto de reunión en vez del baile del palacio real (elementos 6,7 y 8). Aunque Anna Brigitta Rooth hace notar que esta sustitución es muy antigua ${ }^{7}$, no parece ser un elemento predominante. De las cuarenta y una variantes consultadas para el presente estudio ${ }^{8}$ sólo tres versiones la poseen, además de la de Lyra: la jalisciense \#68, «Granadina» de Stanley L. Robe y dos de las

7. Anna Brigitta Rooth, The Cinderella Cycle (Lund: SWK Gleenup, 1951) 211.

8. Aunque es normal entre folkloristas identificar los cuentos por el número de la colección, usaré también el título pues a menudo es connotativo del giro que se le ha dado a la versión en particular. Manuel José Andrade \#150, «María la Cenicienta», \#163 «Mariquita la Cenicienta», \#164 «La mujei [sic] que le hasía el bien a todo el mundo», \#166 «Cuero de mula», \#167 "Cuerito e burro», Folklore de la República Dominicana (Ciudad Trujillo: Universidad de Santo Domingo, 1948); Rafael Ramírez de Arellano \#86, «Cenisosa» [sic], Folklore Portorriqueño (Madrid: Archivo de Tradiciones Populares, 1926) II; Theophilo Braga, «A madrasta», Contos tradicionaes do Povo Portugues (Porto: Universal, 1883) II, 48 II; Paulo de Carvalho 
versiones de Puerto Rico de Mason-Espinosa: «María la Cenicienta» (508) y «La cenizosa» (515).

En cuanto a la prueba de identidad, ya sea por el zapatito u otros medios (puntoIV en Aäme-Thompson y Hansen), no aparece en esta versión de Carmen Lyra. En su lugar un loro (lora) revela el escondite con la cantilena (elemento 10). De las variantes consultadas sólo unas pocas presentan ese elemento con variedad de delatores: un perro en Rael I,\#107, «La Granito de Oro», quien dice: "Guau, guau, la Granito de Oro debajo de la artesa está y la Cuero de Asno en la carroza va" (209). En el \#108 de esa misma colección un gatito dice: "Mi señora la amita la linda abajo de la artesa" (211). También un gato advierte: "¡Miau, miau! Mi ama la linda debajo de la artesa está", en el \#112, «El pájaro verde» (Rael I, 223).

Lo hasta aquí expuesto demuestra que la versión de Carmen Lyra presenta características ajenas al tradicional cuento de «La Cenicienta». El viudo se casa con la viuda por ambición. Cada uno de ellos tiene una hija cuyo distintivo es de fundamental importancia

Neto \#37, «La madrastra», Cuentos folklóricos del Ecuador (Quito: Universidad Central del Ecuador, 1966); Aurelio Macedonio Espinosa \#107, «C6́mo la vianda quiere a la sal», \#108 y \#112, «La zamarra», \#154, «Las tres avellanas», Cuentos populares españoles, I (Madrid: Conse jo Superior de Investigaciones Científicas, 1946) (en las citas de aquí en adelante se usará sólo Cuentos); Jacob Ludwig Karl Grimm \#21, «Ash Girl», The Grimm's German Folk Tales (traducción Francis P. Magoun Jr. and Alexander H. Krappe (Carbondale: Southern Illinois University Press, 1960); Alden J. Mason y Aurelio M. Espinosa, ed. «Porto-Rican Folklore: Folk Tales; «La Cenicienta», siete versiones», Journal of American Folklore (en adelante: $J A F$ ), XXXVIII (1925) 507-615; «Los tres trajes», cuatro versiones, op. cit, 572-578; Juan B. Rael \#106, «La Cenicienta golosa», \#107, «La Granito de Oro», \#108, «La envidiosa», \#109, «El torito azul», \#1 14, «Pá jaro Verde», \#116, «María», \#118, «La muchacha encantada», \#237, «El toro pinto», Cuentos españoles de Colorado y Nuevo Méjico (Stanford: Stanford University Press, 1951) I y II; Stanley L. Robe \#68, «Granadina», \#69, «María Cenicienta», \#70, «María Cenicienta», Mexican Tales and Legends from Los Altos (Berkeley: Folklore Studies 20, University of California Press, 1970); Yolando Pino Saavedra, «María la de la estrella de oro en la frente», Cuentos folklóricos de Chile, II (Santiago: Ediciones de la Universidad de Chile, 1961) 256. Versiones no incluidas en los índices y, por lo tanto, aportes de este estudio: Luis de Câmara Cascudo, «Bicho de Palha», "Almofadinha de oro», Contos tradicionals do Brasil (Rio de Janeiro: America Editora, 1946) 64 y 92; Luis Felipe Ramón y Rivera e Isabel Aretz, «La niña bonita y la niña fea», Folklore Tachirense (Caracas: Biblioteca de autores y temas tachirenses, 1961) 226; Mario Riera Pinilla \#20, «La madrastra envidiosa», Cuentos Folklóricos de Panamb (Panamá: Departamento de Bellas Artes, 1956). 
dentro del desarrollo del cuento: una es rubia, la otra negra (elemento 1). Se ha reemplazado la varita mágica u otro objeto sobrenatural por la muñequita, que es en realidad la Virgen (elemento 3$)^{9}$, la cual se vale de la arquita para proveer a su protegida de vestidos maravillosos (elemento6), y la aconseja cuando se hace necesario(elementos 5, 11, 12). Los elementos $8,9,13,14,15$ y 16 son exclusivos de esta versión.

Hasta el título deja de ser «Cenicienta». El de «La negra y la rubia» recuerda al del cuento-tipo 403, «The Black and White Bride» (Aäme-Thompson y Hansen), donde también aparecen una madrastra cruel y una hijastra que, por su buen corazón, es recompensada con la mano de un príncipe.

A pesar de las alteraciones apuntadas, el cuento de Carmen Lyra ha conservado la esencia de «La Cenicienta». Difiere bastante de las otras versiones en cuanto a la adaptación al medio y las costumbres costarricenses que introduce la autora.

«La suegra del Diablo» (98-106)

Este cuento aparece clasificado bajo el cuento-tipo *340 en los índices de Boggs y Hansen. Boggs lo especifica como sigue:

«Devil's Mother-in-Law.» Exasperated mother wishes her lazy daughter may marry the Devil. A handsome stranger appears and marries her. He is suspected of being the Devil. On bridal night mother has daughter close all openings to bridal chamber except the keyhole, and has her sprinkle husband with holy water or beat him with blest olive branch saying this will insure his fidelity, or that wife will be boss. He is really the Devil and flees through keyhole, but mother catches him in a flask as he comes out. For years peace reigns on earth while Devil is

9. La Virgen reemplaza a la madre que, ya muerta, en la mayoría de las versiones del cuento-tipo 510A, transmigra, por decirlo así, a la forma de árbol, animal, etc., para socorrer a la desgraciada huérfana. 
prisoner in flask. Finally a soldier releases him. They agree Devil will enter princess and make her sick; soldier will pose as doctor, Devil will leave and king will reward soldier for the cure. Devil refuses to leave until soldier frightens him away by saying that his mother-in-law is coming. Or by cutting off a piece of devil's tail and threatening to take it to mother-in-law, soldier is able to induce him to pay reward.

En Cuentos de mi tía Panchita aparecen los siguientes elementos:

1. Una viuda acomodada quiere casar a su hija con un hombre rico.

2. Pasa por la calle un caballero con toda la dentadura de oro, y un caballo con ameses de oro y cascos de plata.

3. Aparece dos veces más, cada una en un caballo más lujoso.

4. La tercera vez se detiene. Lo invitan a entrar, hablan de sus riquezas y el caballero pide la mano de la muchacha.

5. Se celebra la boda. Al entrar el cura "el novio tiene intenciones de salir corriendo" (100), lo que pasa desapercibido.

6. Una vez casados, el marido entretiene a la esposa "caminando por paredes y cielo raso con la facilidad de una mosca" (101).

7. La hija cuenta esas proezas del esposo a la madre, quien sospecha la identidad del yemo.

8. Cuando la suegra vuelve a visitarlos, trae consigo una botijuela y pide al yemo que demuestre sus habilidades sobrenaturales entrando en ella. Inmediatamente que lo hace, la suegra cierra la tapadera y él queda atrapado.

9. Se entierra la botijuela en un hoyo en la montaña.

10. Desde ese momento sólo se cometen pecados veniales en el mundo, "aconsejados por los diablillos chiquillos" (102).

11. Años después pasa por ahí un pobre leñador agobiado de hijos. Oye voces. Es el Diablo quien lo convence, con promesas de hacerlo rico, para que levante la tapadera. 
12. Una vez libre, el Diablo expone su plan: el Diablo entrará en el cuerpo de una persona y saldrá de ella cada vez que el leñador - -que se hará pasar por médico- diga al oído del enfermo: "Yo soy el que te sacó de la botijuela" (103), pero le advierte que no insista cuando él se niegue a salir.

13. Después de curar a duques y marqueses, el rey solicita sus servicios para la reina que se ha vuelto loca. El leñador, para darse importancia, dice que si él no es capaz de curarla, le puede cortar la cabeza.

14. Esta vez el Diablo se niega a salir. El hombre, después de rogar en vano, pide al rey que se haga mucho ruido con latas y pólvora. $\mathrm{Al}$ oír tanta algazara, el Diablo quiere saber la causa, y el supuesto médico le explica que es su suegra que ha averiguado donde está y viene a llevárselo. Ante seme jante amenaza, el Diablo salió corriendo y "no paró hasta llegar al infierno" (106).

Esta versión de Carmen Lyra se diferencia en la motivación del cuento-tipo y de las otras diecinueve versiones consultadas ${ }^{10}:$ la madre desea casar a la hija con un hombre rico sin ser requisito el que tenga dientes de oro, aunque en efecto los tiene (elementos 1 y 2). En las siguientes versiones, la hija es la que está ansiosa de casarse con:

1. Un hombre con dentadura de oro: Andrade \#70, \#71, \#74 y \#75; Mason-Espinosa \#51.

10. Andrade \#55, «El joven de los dientes de oro», \#70, «El joven de lo' diente de oro», \#71, «El galán de los dientes de oro», \#72, «El joven de lo diente de oro», \#73 «María y su tre helmanito», \#74, «El hombre de lo diente de oro», \#75, «La boda de la olguyosa»; Francisco Xavier Ataide Oliveira, «A sogra do Diabo», Contos Tradicionaes do Algarve (Tavira, Portugal: Typographia Burocratica, 1900) I, 400-402; Fernán Caballero, «La suegra del Diablo», «Juan Holgado y la Muerte», Cuentos Andaluces (Madrid: Alcalá, 1966) 129-136, 123-128 respectivamente; Alden J. Mason, A. Mason-Espinosa, \#51, 52, 53, «La joven que se casó con el diablo», $J A F, \mathrm{XL}$ (1927), 359-360. Variantes que no aparecen en ninguno de los índices conocidos y que, por lo tanto, constituyen aportaciones del presente estudio son: Nicolás Maquiavelo, «Belfagor: Novella del demonio che presse moglie», Novelle Italiane (ed. Robert A. Hall, Jr., New York: Bantam, 1965) 26-44; Pino Saavedra I (1960), \#34, «La suegra del diablo»; Howard T. Wheeler \#152, «El pobre y el diablo», Tales from Jalisco, Mexico (Philadelphia: American Folklore Society, 1943) 443-451. 
2. Un joven que escupa manzanas de oro: Andrade \#76.

3. Un joven con dentadura de oro y cabello de plata: Andrade \#76, Wheeler \#183 (en esta versión es la madre la que así lo requiere).

4. Una joven cansada de estar soltera se casaría aunque fuera con el Diablo: Wheeler \#153 (en esta versión no hay mención de dientes de oro o plata).

Solamente en la versión de Tía Panchita y en la argentina citada por Hansen (*340 RINT, 232-235), la suegra atrapa al Diablo induciéndolo a demostrar cómo entra en la botijuela o botella, según el caso (elemento 8).

En la mayoría de las versiones consultadas hay un marcado énfasis moralizador o religioso con personajes enviados del cielo, agua bendita y ramas de olivo. En la de Fernán Caballero, por ejemplo, la llegada del diablo-pretendiente se debe a la maldición de la madre: "Por su lado la tía Holofernes, mientras más admiraba a su yerno más le miraba de reojo ... y recordaba con recelo aquella maldición que echó a su hija" (131). La suegra aconseja a la hija que le pegue al marido con una rama de olivo bendito con el pretexto de que "en la alcoba manda la mujer y sirve para sancionar y establecer ese mando" (131-132). Pero al ver el marido la rama de olivo y

no viendo más escapatoria que el agujero de la llave, se coló por él como una puerta cochera, porque habrán ustedes caído, así como lo sospechó la tía Holofernes, en que aquel mozo, tan rubio y blanco y tan bien hablado era ni más ni menos que el diablo en persona, el cual, usando del derecho del anatema que contra su hija lanzó la tía Holofernes, quería regalarse con los obsequios y regocijos de una boda, cargando luego con su mujer, haciendo así en beneficio propio, lo que tantos maridos le suplicaban hiciese en el de ellos (132).

El cuento de Andrade \#70 termina diciendo: "Y eso le pasó a la muchacha po desile mentira a su papá y que po cuenta de eya po poco 
embroma su do helmana" (143). Y en la versión \#71 la hija le dice a la madre: "Yo no siendo con uno que tenga lo diente de oro no me caso" (143). El de los dientes de oro resulta ser el Diablo, y un hermanito que resulta ser "un ángel del cielo" (143) la salva al final. Igualmente en el \#72 y \#73 la joven se salva del Diablo por medio de un hermano o hermana, y en el \#74 es un viejito que resulta ser Dios. Sólo en el \#75 la muchacha no se libra del castigo, y el Diablo "la cosina [sic] y se la come en compañía de lo diablito" (147). En el \#76 "el joven de lo diente de oro y lo cabello de plata, se volvió un burro y se puso a rebulnal, y la muchacha le dio un ataque, y el Diablo le dijo que ahí tenía lo cabeyo de plata y lo diente de oro" (148). La muchacha acaba casándose con un labrador.

En la versión portuguesa de Athaide una lavandera, cansada de las presunciones de la hija, le desea:"-Deus quiera que cases já, ainda que seja con o diabo" (400). Este se presenta, se prepara el casamiento, pero luego, sin más razones, la madre le dice a la hija: "Não estou convencida de que ele seja um homen" (401). Se va a la iglesia y a su regreso "pozse ella a queimar incenso, alecrim e resmono, e poz no buraco da fechadura una infusa pequena" (401). El Diablo se convierte en humo, y la hija lo empuja por el hueco de la cerradura y queda atrapado.

En la versión que nos concieme, casi no existe el aspecto moralizador-religioso, destacándose más la astucia de la suegra:

La esposa quiso intervenir para que le abrieran [el Diablo daba gritos desaforados dentro de la botijuela], pero la madre le dijo: - ¿Pues no ves que es el mismo Pisuicas? Desde la otra vez que estuve, eché de ver que tu marido no era como todos los cristianos. Le consulté a un sacerdote, quien me acabó de convencer de que mi yemo no era sino el Malo. Dale infinitas gracias a Nuestro Señor de que a mí se me ocurriera este medio de salir de él (102). 
Con el entierro de la botijuela y el Diablo adentro (elemento 9), termina la intervención de la suegra. El Diablo aparece de aquí en adelante en primer plano. Se podría decir que, folkclóricamente, se introduce un nuevo tema que correspondería a los cuentos-tipo 331 «The Spirit in the Bottle» y 332 «God Father Death. The man as a doctor...» de Aäme-Thompson: el Diablo sustituye a la muerte en la versión de Lyra.

Ambos temas han sido utilizados literariamente. El más conocido de la literatura castellana es el Diablo Cojuelo (tipo 331). Pero más íntimamente ligada al cuento que aquí se estudia está la versión de Maquiavelo, «Belfagor: Novella del demonio che prese moglie», aunque con diferente motivación: Belfagor, uno de los diablos que cayeron del paraíso al infierno, debe convertirse en hombre para corroborar en el mundo de los humanos, lo que atestiguan las almas que llegan al infierno: que la mujer fue la causa de su condena.

Este segundo tema (el diablo embotellado y el médico fingido) se incluye solamente en las versiones «La suegra del Diablo» de Caballero(129-136), Pino Saavedra \#34, Wheeler \#153 y la argentina descrita por Hansen, además de la de Maquiavelo. En «Juan Holgado y la Muerte» de Caballero (123-128) y Wheeler \#152, así como «El pobre y el diablo», el hombre que se finge doctor es el punto central sin intervención ninguna de la suegra y la hija.

El elemento 16, es decir, el engaño del Diablo por el supuesto médico haciéndole creer que viene la suegra (o esposa), aparece únicamente en «La suegra del Diablo» de Caballero y la versión de Maquiavelo. Esto pareciera indicar que es un elemento exclusivo de las versiones literarias, lo cual hace pensar que tal vez estas fueran las fuentes del mismo elemento en Carmen Lyra. Cada autor relata el pasaje con detalles de su propia cosecha:

Briones [el soldado que puso en libertad al Diablo en Caballero], dio orden en nombre de la princesa que repicaran las campanas de la ciudad. Cuando volvió a la estancia real, el diablo que 
aborrece de muerte el sonido de las campanas y que, además, es curioso, preguntó a Briones:

- ¿A qué santo es el repique?

— Repican —, respondió el soldado_ por la llegada de vuestra suegra, que he mandado a llamar.

Apenas oyó el diablo que llegaba su suegra cuando echó a huir . con tal rapidez que ni un rayo de sol le hubiera alcanzado ${ }^{11}$.

...fatto il cenno col cappello, tutti quegli suoni, e con moreggiare diputati, dettono in quegli suoni e con romori che andavono al cielo ne vennono vero i palco. Al quale romore alzó Roderigo [el diablo-hombre] gli orecchi, e non sapiendo che cosa fusse e stando forte maravigliato, tutto stupido domando Gianmatteo [el pretendido médico] che cosa quella fusse. Al quale Gianmatteo tutto turbato disse:

-Oimé, Roderigo mio, quella è mógliata tua, che ti viene a ritrovare!

...non pensando s'egli era possibile o ragionevole se la fusse, dessa, senza replicare altro, tutto spaventato se en fuggì, lasciando la fanciulla libera; e volse piu tosto tomarsene in inferno a rendere ragione delle sue azione, che di nuovo, con tanti fastidii dispetti e periculo, sottoporsi al giogo matrimoniale ${ }^{12}$.

Y en la versión de Lyra:

Cuando estaba para terminar el plazo, se le ocurrió una idea: pidió al rey que hiciera traer la banda, que comprara triquitraques y cohetes, que a cada persona del palacio le diera una lata o algún trasto de cobre y la armara de un palo y que a una señal suya, la banda rompiera con una tocata bien parrandera, todos

11. Caballero, 136.

12. Maquiavelo, 44. 
gritaran y golpearan en sus latas y se diera fuego a la pólvora (...). Y así se hizo. En este momento se acercó el leñador al oído de la reina y le suplicó al Diablo: — iSalí por vida tuyita...-En vez de contestar, el Diablo preguntó: -Hombré, ¿qué es ese alboroto? El otro respondió: -Aguardate, voy a ver qué es-(...)¡Que Dios te ayude! Es tu suegra que ha averiguado que estás aquí y ha venido con la botijuela para meterte en ella de nuevo(105-106).

El Diablo entonces exclama: "¿Quién le iría con la cavilosada a la vieja de mi suegra? ... ¿Y patas para qué las quiero? Salió corriendo y no paró sino en el Infierno" (106).

«La suegra del diablo» de Tía Panchita concuerda, pues, con las versiones folklóricas y literarias en lo esencial de los elementos 1,2 , $8,9,11,12,13$ y 14 , pero excluye totalmente la sátira aguda contra las suegras (o esposas). Son exclusivos de esta versión los elementos 3,4 , 5,6 y 10. Con ellos la narración adquiere más colorido y humor sin alterar su esencia.

«El tonto de las adivinanzas» (17-24)

Corresponde al cuento-tipo 851 «The Princess Who Cannot Solve the Riddle» en los índices de Hansen y Aäme-Thompson. Este último especifica los elementos como sigue:

I. The Riddle Contest. A princess is offered in marriage to the youth who can propose a riddle which she cannot solve.

II. The Clues. On the way to the contest, the hero is given a clue. He sees a horse poisoned and then eaten by twelve men who die of the poison.

III. The Riddle. a) The hero propounds the riddle: «One killed none and yet killed twelve,» or b) the riddle of the unborn, or c) of the murdered lover. 
IV. The Princess Won. a) The princess tries to find the answer by visiting him at night and leaming it from his dreams. He is, however, aware of the visit, keeps a token, and proves that she has visited him.

El de Carmen Lyra es como sigue:

1. Una viejita tiene un hijo "vivo" y otro "tonto".

2. El rey ofrece casar a su hija con el que proponga tres adivinanzas que Su Majestad no pueda contestar y le adivine otras tres propuestas por el rey mismo.

3. El tonto decide competir y la madre trata de disuadirlo pero sin resultado.

4. El tonto ensilla su yegua Panda y la madre le prepara una torta de arroz y huevo. Está un poco ciega y en vez de orégano para condimentar, coge unas hierbas que son venenosas.

5. Cuando el tonto siente hambre, desmonta para comer, y como no hay hierba a su alrededor para la yegua, le da la torta. La yegua cae muerta.

6. El muchacho "le hace duelo" (19) a la bestia y mientras tanto unos perros le lamen el hocico y se envenenan.

7. Mientras cava un hoyo para enterrar a Panda, siete zopilotes comen de los perros muertos y también mueren.

8. De lo sucedido el tonto saca su primera adivinanza: "Torta mató a Panda, / Panda mató a tres/ tres muertos mataron a siete vivos" (21).

9. En el camino se encuentra una vaca que se había despeñado. La acaba de matar, asa el ternerito, pues estaba preñada, y se lo come. Hace su segunda adivinanza: "Comí came de un animal que no corría sobre la tierra, ni volaba por los aires, ni andaba en las aguas" (21).

10. Bebe luego el agua de un coco y formula su tercera adivinanza: "Bebí agua dulce que no salía de la tierra, ni caía del cielo" (21).

11. En el palacio se burlan de él, el rey trata de disuadirlo y la princesa, horrorizada, le hace ver que para casarse con ella tendrá que vestirse y calzar como los señores. El tonto sigue insistiendo. 
12. El rey no puede adivinar lo que le propone el tonto.

13. Cuando le corresponde adivinar al tonto, se rasca la cabeza y dice en voz alta: "Aquí fue donde la puerca torció el rabo ..." (22). El rey, que había encerrado un rabo de puerco en una caja de oro, lo toma por la respuesta correcta.

14. La segunda vez dice: "¡Ah caray! ¡Y en qué apuros tienen a este pobre Grillo!" (así lo apodaban en el lugar) (22). El rey acepta su respuesta pues tenía un grillo encerrado en su puño.

15. A la tercera pregunta dice en su desesperación: "Bien me lo dijo mi mama que buen adivinador de m ... sería yo" (23). Esta vez había bajo lujosos paños, un vaso con estiércol en un suntuoso altar. Se declara al tonto vencedor.

16. Se empiezan los preparativos para la boda, pero la princesa ordena al sastre y al zapatero que hagan las prendas del novio más estrechas de lo que corresponden.

17. Llegado el momento, el tonto se siente incómodo con su indumentaria pero se rehúsa del todo a ponerse los guantes.

18. Prefiere renunciar a la princesa y volver donde su "mama" a vivir y andar como le da la gana.

19. El rey le da dos mulas cargadas de oro de compensación.

Aurelio M. Espinosa en Cuentos II (81), concluye que de las ciento once versiones hispánicas que él estudió, sesenta y nueve son verdaderas versiones del tema fundamental. Entre ellas clasifica la de Carmen Lyra. Esta versión se diferencia de ese tipo I de Espinosa en los siguientes elementos:

1. No se trata de un pastor sino de "El Grillo" al que se considera tonto.

2. El Grillo se marcha para el palacio del rey con una "torta" (tortilla) de arroz y huevo que fue envenenada involuntariamente.

3. Panda se come la torta y muere. Tres perros le lamen el hocico y mueren también (en vez de tres aves). Siete zopilotes comen de los 
perros con el mismo resultado (en la clasificación B1 de Espinosa son siete ladrones u otros hombres los que se comen los grajos envenenados y mueren).

4. Los incidentes del camino son diferentes, variando las adivinanzas.

5. Se ha eliminado el pasaje picaresco (presente también en Aärne-Thompson, sección IV): las visitas de las criadas y la princesa misma al cuarto del contendiente.

6. Hay en su lugar una innovación: el rey propone a su vez tres adivinanzas que el Grillo adivina por casualidad. Ninguna de las ciento dos versiones consultadas para el presente estudio presenta este elemento $^{13}$. Sin embargo, en el cuento «El Grillo adivino» (Espinosa, Castilla) esta interpolación constituye el elemento fundamental.

7. No hay matrimonio en esta versión de Carmen Lyra. Aunque el tonto sale victorioso de la contienda, renuncia a casarse con la princesa pues prefiere sentirse libre de andar como le plazca:

Mucho me gusta su hija, pero más me gusta andar a gusto. Me comprometí a casarme con ella si me vestía de señor, pero yo no sé cómo hacen para andar con los pies bien chimaos, con el

13 Versiones encontradas en el transcurso de esta investigación, no incluidas en ninguno de los indices conocidos; Argentina: Chertudi \#56, «Torta mató a Panda», \#71, «Uno mató a Chepa», \#72, «Adivinanza en forma de cuento»; Chile: Pino Saavedra II, \#113, «El cuento de las adivinanzas», \#114, «El cuento de las adivinanzas», \#115, «Uno mató a Paula»; Cuentos (1963) III, "Chiste de una princesa», 401; Ecuador: Carvalho Neto, «Apunté al que vi y maté al que no vi», Cuentos, 147; Venezuela: Ramón y Rivera, «El rey, la hija y el bobo o la adivinanza de Floripa», 301. Otras versiones consultadas: Arellano \#22, «La princesa adivinadora», \#23, «La adivinanza», \#24, «La princesa de las adivinanzas», \#25, «La princesa adivinadora»; Athaide Oliveira I, «João Reguinjote», 116, «O João pastor», 122; Braga II, «A princesa que adivinha», 134; Câmara Cascudo, "A princesa adivihona», 376; Espinosa \#5 «El acertijo», \#6, \#7, \#8, ba jo el mismo título, en Cuentos I; \#2, «El tío Grillo», Cuentos populares de Castilla (Buenos Aires: Espasa Calpe, 1946) 18-25; «La adivinanza del bobo», JAF, XLII (1929), 164; MasonEspinosa, «Porto-Rican Folklore»: a) «Juan el grillo y el rey», b) «Lauro y el grillo», c) «El adivino», d) «Don Pedro el grillo», JAF, XXXVII (1924) 289-291; Mason-Espinosa, «Ciclo de Juan el Bobo», 70 versiones, JAF XXXIV (1921) 146-207; Rael I, \#5, «El pastor», \#6, «La adivinanza»; Silvio Romero, "O Matuto João», Contos populares do Brasil (1897, Rio de Janeiro: Livraria Jose de Olympio, 1954) 232-236. 
pescuezo metido entre esta vaina, bien echados para atrás, que les tiene que doler la caja del cuerpo... Prefiero volverme donde mi mama: allá ando yo como me da mi gana; y si me quedo aquí tendría que pasar mi vida como un Niño Dios en retoque (24).

La autora explica en una nota al pie de la página que para retocar esas sonrientes esculturas que representan al Niño Dios, "las aseguran con un tornillo que les meten por detrás".

El tonto vuelve a su madre y a su hermano que lo reciben muy contentos. Es, pues, un final feliz pero dentro de la realidad, si se excluye lo de los sacos de oro que el tonto recibe, tal vez para mantenerse más dentro del plano de lo maravilloso. Este elemento aparece en el índice de Hansen bajo $851, I V^{*}$ c: "He accepts money instead of princess."

En las ciento dos versiones consultadas no se encontraron los siguientes elementos de la versión de Carmen Lyra: 4 (en parte), 11, 13 (parcialmente), 15, 16, 17, 18. O sea que en ella no hay intento premeditado de envenenamiento por parte de la madre, ni pasajes escabrosos. Y difiere en el texto en el número de las adivinanzas, así como en el tono general del cuento, que es humorístico en vez de obsceno.

«Juan el de la carguita de leña» (36-41)

Este cuento no parece tener paralelos en la tradición oral del Viejo ni del Nuevo Continente. No se encuentra ningún cuento-tipo que concuerde exactamente con él, ni ninguna versión cuyo tema se le aproxime. En esencia, este es el argumento:

Una viejita tiene tres hijos: dos, "vivos" y uno "tonto". El tonto va a la montaña a recoger una carguita de leña para la madre. Se le aparece una viejita que le da una varillita. Gracias a ella, la carguita de leña hace las veces de vehículo y vuelve a su casa montadoen ella, pero Juan guarda el secreto de lo sucedido. La hija menor del rey pierde un 
anillo "nunca visto" al bañarse en el río. El rey promete la mano de su hi ja a quien lo recobre. Nadie lo puede recuperar, sólo Juan lo logra con ayuda de su varillita. El rey cumple su promesa al muchacho a pesar de las súplicas de la princesa. El día de la boda la carguita de leña se transforma en verdadera carroza, Juan en un hermoso príncipe, su casilla en un palacio y su madre en gran señora, todo por obra y gracia de la 'varilla'. Juan y su esposa llegan a ser reyes. Sus hermanos, antes unos parranderos inútiles, son ahora personas serias y esposos de princesas.

El único cuento-tipo que concuerda ligeramente con el descrito es el 560 de Aäme-Thompson, «The Magic Ring»:

I Magic Object Received. The hero receives a magic ring which will perform all the wishes of the owner.

II Magic Castle. By means of his wishing ring, he builds a magic castle and marries the King's daughter.

III (Se omite porque no tiene relación con el cuento de Lyra).

IV Recovery of the Object. a) The hero recovers the missing object with the help of the grateful cat and dog, etc.

Los paralelos son pocos: en el de Carmen Lyra falta la mayoría de los elementos fantásticos como el castillo mágico, el robo del objeto mágico y su recuperación con la ayuda del gato o perro agradecidos por haberlos protegido.

Además de no tener paralelo en la tradición oral, este cuento es una excepción dentro del conjunto que forma esta colección, porque expone claramente una enseñanza. "Los dos 'vivos' eran muy ruines con la madre y nunca le hacían caso, pero el tonto era muy bueno con ella y era el palito de sus enredos" (36). Por eso es premiado. La viejita de la montaña lo dice explícitamente: "-Mirá Juan, aquí te traigo esta varillita de regalo. Es como un premio por lo sumiso que sos con tu mama" (37).

Hay también declaraciones sentenciosas: "El tonto no era nada tonto, pero como era tan bueno lo creían tonto" (37). Cuando el rey 
trata de calmar a la desolada princesa porque tiene que casarse "con aquel infeliz" (39), le da una lección de humildad:

[El rey] cogió a su hija menor por su cuenta y se puso a aconse jarla con muy buenas razones, porque este rey no era nada engreído: - Vea, hijita, a nadie hay que hacerle ¡che! en esta vida. No hay que dejarse ir de bruces por las apariencias¡Quien quita que le salga un marido nonis! Y en esta vida uno se hace ilusiones de que porque a veces se sienta en un trono es más que los que se sientan en un banco. Pues nada de eso, criatura, que sólo Cristo es español y Mariquita señora (39).

Aunque este cuento no tenga precedentes en el folklore de otros países, es folklórico en espíritu, está de acuerdo con los otros cuentos de la colección en el tono, el léxico y la técnica narrativa.

«El Cotonudo» (77-88)

En ninguno de los índices hasta ahora publicados aparece un cuento-tipo que concuerde con el cuento de Carmen Lyra, «El Cotonudo», cuyos elementos son los siguientes:

1. Una viejita tiene un hijo bueno y sumiso, cuya ambición era ser médico. Para pagarle los estudios ella hacía de lavandera.

2. La princesa, que lo veía pasar todos los días frente al palacio con su traje muy remendado pero limpio, sus pies descalzos pero bien lavados, una alforjita al hombro y unos libros bajo el brazo, andaba intrigada, quería saber quién era y lo hizo llamar un día.

3. De ahí en adelante lo esperaba en el jardín para conversar y acabó por enamorarse de él, "por su sencillez y facilidad de palabra".

4. La princesa que, era bella y amable, también causó que el muchacho se enamorase de ella pero, comprendiendo lo insensato de ese amor, se guardaba muy bien de exteriorizarlo. 
5. Al fin la princesa toma la iniciativa y, aunque el muchacho se resiste, acaba por convencerlo de que acepte una bolsa de monedas de oro y se vaya a "tantear fortuna" (79).

6. Así lo hace con tan mala suerte que naufraga el barco en que regresaba, salvándose él "por un milagro" (79).

7. Vuelve a su país $y$, al caer la noche, se pone un gran sombrero y un cotón ${ }^{14}$, los dos únicos objetos que había traído de su viaje, y sale para entregar a la princesa una carta en la que le explica lo sucedido, y le pide no lo espere más.

8. Lagente se preguntaba a su paso: "— ¿quién seráese Cotonudo?".

9. La princesa lo convence para que parta de nuevo con más dinero, y esta vez unos ladrones dan buena cuenta de lo que llevaba.

10. Regresa a su país y vuelve a ponerse su cotón y su sombrero y a buscar a la princesa, y la gente a preguntarse quién sería ese Cotonudo.

11. Por tercera vez la princesa lo convence para que parta con más oro. Pero "por lo que se ve era más torcido que un cacho de venado" (80), hubo una tempestad "que se tragó el barco" (80). Fue arrojado a una isla desierta, "sin más vestido que aquel con que Nuestro Señor lo echó a este mundo" (80).

13. En el colmo de la desesperación se prepara a colgarse de un árbol cuando, en medio de la corriente de un río que corre por ahí, ve a un joven sentado en una roca. Lo extraño del suceso lo hace acercarse a investigar y el joven explica que es un príncipe encantado desde hace muchos años. Sólo alguien de mucho valor podría desencantarlo.

14. El Cotonudo reflexiona que "era mejor morir tratando de sacar de apuros a un prójimo que ahorcado" (81) y toma el lugar del joven.

14. Carlos Gagini, Diccionario de Costarriqueñismos (1918, 2a. edición: San José: Imprenta Nacional, 1919): "'Cotón'. Término de germanía equivalente a jubón. En Costa Rica es una prenda, hoy ya muy rara, usada por los montañeses de las regiones frías, especialmente los de Cartago. Es una pieza de lana o de algodón, de dos varas y media de largo con un agujero en el centro para pasar la cabeza". 
15. Aparece entonces en el río una fuerte corriente que se lleva piedras y troncos. El Cotonudo, santiguándose, espera ser arrastrado por la corriente, pero el agua al tocar sus pies se apacigua y el río entero se seca.

16. Ve luego venir un tigre que "echaba fuego por los ojos y le enseñaba los dientes" (81). Cree no escapar esta vez, se santigua de nuevo y "encomendó su alma a Dios", pero el tigre, como el río, no hizo sino lamerle los pies y desapareció en la montaña.

17. Ahora es un toro "de aspecto tan temible, que hubiera hecho temblar al mismo San Miguel Arcángel, quien no le tuvo miedo ni al Diablo" (82). El muchacho, ya seguro de que tampoco le hará nada, "más bien se rió de los aspavientos del toro" (82).

18. Se oye entonces un gran estruendo, se vuelve la piedra en que estaba sentado y queda frente a la entrada de una cueva.

19. El príncipe, ya desencantado, le besa las manos, y ambos entran a explorar la cueva donde encuentran grandes riquezas.

20. Aparece un barco anclado en el puerto y en él transportan las riquezas al país del príncipe.

21. Los padres del príncipe, ya viejecitos, lo reciben con gran alegría y le ruegan al Cotonudo que se case con una de las princesas, pero él les habla de su compromiso y parte.

22. Vuelve al palacio y se entera de que dentro de poco casarán a la princesa con un príncipe viejo y feo.

23. Se entera la princesa de su llegada y lo hace esconder tras unas cortinas cerca del altar. En el momento dado lo hace salir, declarando que no se casará sino con él. El obispo no tiene alternativa y los casa.

24. Los reyes, furiosos, la visten con andrajos, la ponen puerta afuera y la obligan a montar el burro de un carbonero que pasaba en ese momento.

25. La gente, disgustada, le gritaba a la princesa que se había vuelto loca. 
26. El Cotonudo, con calma, se dirige al puerto, da unas monedas de oro al carbonero que los seguía tristemente y entra en el barco que lo recibe con gran descarga de cañonazos.

27. Lleva a la princesa hacia un salón donde hay una caja con ricas vestiduras para ambos y montan una carroza.

28. La gente ahora grita: " Son el sol y la luna! La princesa se ha casado con el rey más hermoso de la tierra. ¡Hizo bien la princesa en no casarse con aquel vie jo que no es más que un cascarón! ¡Este sí es ñeque!" (87).

29. Van a buscar a la vieja madre del Cotonudo, quien "se daba pellisquitos" (87), y se preguntaba cuándo iba a despertar.

30. Envían ricos regalos a los reyes, quienes ahora le abren los brazos al yerno, $y$ viven felices.

Como ya se dijo antes, los elementos tal y como se presentan combinados en este cuento, no aparecen en ningún cuento-tipo ni en ninguna de las muchas colecciones de cuentos consultadas. Sin embargo, el cuento\#220, «La varita de virtú» (Rael II), y el \#317, «El cotón» (Rael II) presentan unos cuantos puntos de contacto. En el primero, el héroe, un plebeyo como el Cotonudo, pretende también a una princesa. El rey lo somete a tres pruebas que completa gracias a la ayuda de un águila, una hormiga y una serpiente, con las cuales había sido bondadoso. Estas tres tareas son equivalentes a las tres pruebas de valor a que se somete el Cotonudo, quien demostró ser bondadoso, además de valiente. El héroe del \#220 (Rael II) también adquiere ropas, coche y palacio, inclusive para sus padres, pero aquí los obtiene gracias a una "varita de virtú" que le da una viejita (45). (Nótese también las semejanzas con «Juan el de la carguita de leña»). La cercanía del \#317 (Rael II) con «El Cotonudo» está únicamente en el traje del protagonista: "Su vestido noera más de un cotón de jerga hasta los pies" (317). Se casa también con una princesa pero porque el rey se la había prometido a quien la hiciera reír: y él, con una serie de tonterías, lo logró. 
Aunque «El Cotonudo» no concuerda con ningún cuento-tipo, sí presenta varios motivos de los registrados por Stith Thompson ${ }^{15}$ : H 71.102, "Water stands still before a prince" (en este caso un plebeyo): $\mathrm{H} 1400$, "Test of Fear." A person is put to various tests in the attempt to make him show fear"; L 161; "Lowly hero marries princess"; T 55.1, "Princess declares her love for a lowly hero" y T 91. 6. 4, "Princess falls in love with lowly boy."

Hay una característica más de la tradición oral observada en «El Cotonudo»: la repetición en número de tres. El héroe hace tres viajes, tres veces se pone su sombrero y su cotón para visitar a la princesa y se somete a tres pruebas de valor ${ }^{16}$.

«La casita de las torrejas» $(107-111)$

«La casita de las torrejas» no es otro que el conocido cuento de Grimm \#15, «Hänsel y Gretel», clasificado en el índice de AämeThompson como cuento-tipo 327A con los siguientes elementos:

Ia)Children are abandoned by poor parents in the woods, b) but they find their way back by cloth shreds or pebbles that they have dropped, c) the third time birds eat their bread crumbs or grain clue, and d) they wander until they come to a gingerbread house which belongs to a witch.

II The witch has the children imprisoned and fattened. a) [no rige aquí]. b) When the finger is to be cut to test his fatness, the hero sticks out a bone or piece of wood. c) [no rige aquí]. d) The witch is thrown into her own oven.

15. Stith Thompson, Motif-Index of Folk Literature: A Classification of Narrative Elements in Folktales, Ballads Myths, Fables, Medieval Romances, Exempla, Fabliaux, Jestes, Books and Local Legends, 2nd ed., 6 vols. (Bloomimgton Ind., 1955-1958).

16. Se han escrito muchos estudios sobre estas repeticiones. Entre otros Axel Olrik, «Epische Gesetze der Volksdichtung», en Zeitschrift fur Deutsches Altertrum, vol. 51 (1909) 1-12. Trad. de Jeanne P. Steager en Alan Dundes, The Study of Folktales (Englewood Cliffs, N. J.: Prentice, 1965) $129-141$. 
III The children acquire her treasure. They are carried across the water by ducks.

Finalmente los niños llegan a la casa. El padre, que ha enviudado, los recibe con alegría. Los niños muestran los tesoros y viven todos muy felices.

La versión de Carmen Lyra dispone estos elementos de la siguiente manera:

1. Un niño y una niña, que han quedado huérfanos, deciden irse a "rodar tierras" cuando no les queda en casa "ni para encender el fuego".

2. Cansados y atemorizados, se suben a un árbol para pasar la noche y desde su atalaya perciben a lo lejos una lucecita.

3. En la mañana se dirigen hacia esa dirección y encuentran una casita de donde sale un apetitoso olor a miel.

4. El olor proviene de una cazuela con torrejas puesta en una ventana.

5. Los niños hambrientos no pueden evitar la tentación; cogen una, luego otra hasta que se vuelca la cazuela.

6. Cada vez que los niños se acercaban a los dulces, una voz gritaba: " Piscurum, gato, no me robés mis torrejas!".

7. La voz pertenecía a una vieja bruja que los atrapa y encierra en una "jaba" para engordarlos y comérselos.

8. Cada vez que la vieja, medio ciega, les pide que muestren el dedo, sacan un rabito de ratón.

9. Cuando por fin descubre el engaño, los manda a traer agua para "ponerlos a sancochar".

10. Un viejito (Dios) escondido detrás de un árbol (la bruja los vigila desde la puerta) los consuela y les aconseja lo que deben hacer.

11. La vieja pone una gran olla a hervir y una tabla enjabonada que llega a su borde. Les pide que "echen en ella una bailadita". Siguiendo el consejo del viejito, le piden que les muestre ella cómo hacerlo. 
12. Al hacerlo, los niños inclinan la tabla y la bruja cae en la olla y muere.

13. La entierran y luego registran la casa encontrando "barriles hasta el copete de monedas de oro". Y como dice la narradora, "Por supuesto que todo les tocó a ellos" (107).

El elemento 1 difiere del cuento-tipo, cambiando totalmente la motivación de la trama. Ya no se trata del abandono de los niños por unos padres desesperados por la pobreza o una madre desnaturalizada. Fuera de esta versión de Carmen Lyra, sólo en cuatro de las veinticuatro consultadas para este estudio ${ }^{17}$ se exime a los padres de toda culpa. En Andrade \#79 y Coelho «Os meninos perdidos», los niños van a buscar leña y se pierden. De la serie «Los niños huérfanos» (MasonEspinosa), se tropiezan con la vieja en uno, en el otro la bruja se los roba.

El cambio de motivación afecta el final del cuento. No hay regreso al hogar ni nuevas dificultades encontradas al paso después de que se deshacen de la bruja (III del cuento-tipo) en Carmen Lyra (elemento 13). Tampoco hay regreso ni mención de tesoros en Coelho y en uno de la serie Mason-Espinosa arriba mencionados; en el otro, los niños se quedan viviendo en la misma casa de la bruja. Sólo Andrade \#79 sigue de cerca el elemento III del cuento-tipo.

El elemento 10 en Carmen Lyra (327 A III**f en el índice de Hansen), ajeno a Grimm \#15, está presente en cinco versiones. En

17. Andrade \#77, «La mala hermana», \#78, «La madrasta pelvelsa», \#79, «Mariquita y Periquito», \#80, «La bruja», \#81, «Lo tre muchacho y la bruja»; Arellano \#83, «Los dos hermanitos»; Athaide Oliveira II (Oporto, 1905), «A velha e as crianças», 239; Ralph Steele Boggs, «Seven Folktales from Porto Rico»: «Los niños y el ogro», JAF, XLII (1929), 161; Francisco Adolpho Coelho, «Os meninos perdidos», Contos populares portugueses (Lisboa: P. Plantier, 1879) 67-68; Espinosa, «El Palacio del jarancón», Cuentos 1; Grimm \#15, «Hänsel and Gretel»; Mason-Espinosa, «Los niños huérfanos», JAF, XXXIX (1926) 564-603, ocho versiones; MasonEspinosa, «La vie ja de los chicharrones», JAF, XXXIX (1926) 296; Elsie Clews Parsons, «The Deserted Children», JAF, XLV (1932), 358-359; Rael II, Apéndice \#85, «Mercoredito»; Silvio Romero, «João mais Maria», Antologia do folclore brasileiro (3a. edic. ed. Louis de Câmara Cascudo (São Paulo: Martins, 1965) I, 317; Wheeler \#64, «Las tres hermanas», \#97, «El gigante». 
Coelho y en uno de la serie «Los niños huérfanos», el aparecido es un viejito. En el cuento de Ataide Oliveira y «La vieja de los chicharrones» de Mason-Espinosa, es un hombre el que se aparece. Sólo en este último se especifica, como en Carmen Lyra, que el hombre es Dios. En Silvio Romero, la aparecida es Nuestra Señora.

Hay un marcado énf asis religioso en las dos versiones portuguesas de la península (Athaide y Coelho), que está ausente en Carmen Lyra. En el primero, el viejito les pide a los niños que invoquen a Nuestra Señora y a San José cuando empujen a la bruja en el horno; en el segundo, la invocación es a San Antonio:

As crianças encontraram um homem que lhes disse: -Acautelem-se. A lenha é para aquecer o forno, pois que a velha os quer assar. Ella come gente. Quando a velha lhes disser que se sentem na pá do forno, digam que não sabem sentar-se e que lhes dê ella primeiro o exemplo. Entao atirem com a velha ao forno, invocando o auxilio de Santo Antonio ${ }^{18}$.

Voltaram os meninos do mato, e encontraram outra vez a velhinha que lhes disse: "Meus meninos, a bruxa vae aquecer 0 forno para vos assar; ela ha-de dizer-vós que danseis na pá, e vós haveis dizer-lhe: dansae vós primeiro, que é para nós aprendermos: depois ella dansara, e vós, direis: Valha-me Nossa Senhora, e São José, e deitae-a no forno ${ }^{19}$.

Cuando llegaron a la quebrada, les salió de detrás de un palo, un viejito que era tatica Dios, y les dijo: "No se aflijan, mis muchachitos, que para todo hay remedio. Miren, van a hacer una cosa: ahora van a llegar con el agua y se van a mostrar muy sumisos con la vieja. Y hasta procuren quedar bien: aticen el

18. Athaide, 242.

19. Coelho, 68. 
fuego, bárranle la cocina, friéguenle los trastos. Ella ha de poner una gran olla sobre los tinamastes y una tabla enjabonada que llegue a la orilla de la olla y apoyada en la pared. Les ha de decir que echen una bailadita sobre la tabla, pero es, que sin que ustedes se den cuenta, va a inclinar la tabla y ustedes van a resbalarse y van a ir a dar entre la olla: así la bruja no tendrá que molestarse oyéndolos gritar y hacer esfuerzos por escaparse (Lyra, 110).

Así pues, el tratamiento de los elementos 10, 11 y 12 en Carmen Lyra se asemeja al de estos cuentos portugueses con presentación más realista en el 10. Se aproxima igualmente a la versión brasileña de Silvio Romero, pero sin otros elementos sobrenaturales que se agregan a esta:

Os meninos foram buscar lenha, e quando vinham toparam con Nossa Senhora, que lhes dises: "Aquela velha é feiticeira e quer dar cabo de vós: portando quando ela mandar fazer a fogueira, fazei-a; assim que vos mandardançar, dizei-lhe: "Minha avozinha, vosemecé dance primeiro para nos sabermos como havemos de dançar". Quando ela estiver dançando, empurrai-a na fogueira e correi" ${ }^{20}$.

Además les dice que han de subirse a un árbol, pues de la cabeza de la bruja saldrán tres perros que querrán comérselos, pero ellos deberán echarles del pan que Nuestra Señora les da, y los perros se convertirán en sus guardianes. La trama se complica más con la ingratitud de María, la niña.

En «La vieja de los chicharrones» de Puerto Rico, el "hombre que es Dios", les dice: "Esa agua y esa leña es para matarlos a ustedes; les va poneruna tabla y les va a decir que bailen y ustedes díganle que

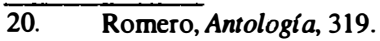


no saben bailar; aflójenle la tabla". La otra versión puertorriqueña de la serie «Los niños huérfanos» lo expresa casi en los mismos términos.

El elemento 6 también muestra semejanzas en su tratamiento con las versiones brasileño-portuguesas: "e a bruxa, julgando ser o gato que as tirava, dizia: 'Sape, gato lambião; / logo te deo teu quinhão" ${ }^{21}$, y en la siguiente: "Psit, o gato arrenegado/ Deixa a filho amasada/ Ella a ti não te pertenece/ E'pr'a mim, não tenho nada" ${ }^{22}$. Pero el mayor grado de aproximación está en la versión brasileña: "Chipe, gato, minha gato, não me furtes meus bolinhos" 23 .

En conclusión, el cuento «La casita de las torrejas» es una variante de «Hänsel y Gretel» ${ }^{24}$. En su tratamiento presenta más puntos de contacto con las versiones de Brasil, Portugal, tres de las de Puerto Rico y una de la República Dominicana en el elemento 1 , y con las de los tres primeros en cuanto a $6,10,11,12$ y hasta cierto punto con 13. Sólo en Carmen Lyra aparece el detalle tan natural de darle sepultura a la bruja.

«Salir con un domingo siete» (141-148)

El cuento-tipo 503, «The Gifts of the Little People» (AämeThompson y Hansen), consiste en los siguientes elementos:

I The Dwarfs' Favor. a) A wanderer takes part in a dance of the witches or people from below the earth or plays for them; or b) adds to their song by naming more days of the week; or c) complacently lets them cut his hair and shave him.

II The Reward. a) They remove his hump; or b) give him gold.

III The Companion Punished. a) His avaricious and bungling companion is given the hump; or b) receives coal instead of gold.

21. Coelho, 67.

22. Athaide Oliveira, 241.

23. Romero, 318.

24. Aurelio Espinosa hace notar que el 39 por ciento de las versiones hispánicas (Portugal y Latinoamérica) son versiones de Grimm \#15, Cuentos II, 430. 
«Salir con un domingo siete» pertenece a este cuento-tipo. Sus elementos son los siguientes:

1. Hay dos compadres: uno mezquino y rico, el otro pobre. Ambos son "güechos" (tienen bocio).

2. El compadre pobre, que acostumbraba cortar leña los viernes para venderla en la ciudad, se perdió en la montaña y se le hizo de noche allí. Se subió a un árbol a esperar el día.

3. Divisó una luz y se encaminó hacia ella. De una gran casa iluminada salía gran algazara. Se introdujo en ella, y después de atravesar muchas salas vacías, llegó a una donde muchas brujas feas y "mechudas" brincaban y cantaban: "Lunes y martes y miércoles tres".

4. Así continuaron por largo tiempo y, como no cambiaban de estribillo, el compadre que permanecía escondido, ya cansado del mismo son cantó "con su vocecilla de güecho": "Jueves y viernes y sábado seis".

5. Inmediatamente comenzaron todas a gritar y a buscar a quien, según ellas, había arreglado tan bien su canción.

6. Cuando por fin lo encontraron, el pobre hombre "estaba en un temblor".

7. Decidieron cortarle el bocio en recompensa, y así lo hicieron sin que el hombre sintiera el mínimo dolor o derramara una gota de sangre.

8. Le dieron también unos talegos de monedas de oro que él cargó en su burra.

9. Cuenta la aventura a su esposa y la manda donde el compadre rico a pedirle prestado un "cuartillo" para medir el oro.

10. La comadre, sospechando algo, untó de cola el fondo de la medida.

11. Cuando encontró unas monedas pegadas a la cola, la comadre rica no dejó en paz al marido hasta que este fue a averiguar cómo había conseguido el oro. 
12. El compadre pobre le cuenta lo sucedido y el rico, aconse jado por su mujer, hace lo mismo.

13. Se esconde en la casona y decide añadir a la cantilena: "domingo siete".

14. Las brujas, al oír aquello, empezaron a "jalarse las mechas" y a gritar furiosas que quién era el atrevido que había echado a perder su canción.

15. Cuando lo encontraron lo sacaron a "trompicones y jalonazos". Una de ellas salió y volvió con el bocio del otro compadre y "se lo plantó en la nuca en donde se pegó como si allí hubiera nacido".

16. Le quitaron la leña a las mulas y las dejaron irse.

17. Cuando el compadre rico llegó a su casa "con dos güechos, todo dolorido y sin sus cinco mulas (...) a la vie ja se le regaron las bilis y tuvo que coger cama" (146).

Aunque «Salir con un domingo siete», como ya se dijo, pertenece al cuento-tipo 503, los elementos 8 , 9 y 10 forman parte del cuentotipo 676, «Open Sesame»:

A poor man observes robbers who enter into a mountain. Uses, like them, the words "open up" and gets gold from the mountain. His rich brother tries to do the same thing but is killed. The rich brother lends his money scales to the poor brother; a piece of money remains in the scales and thus betrays the secret.

25. Andrade \#144, «El rico y el pobre»; Braga \#82, «Os corcundas»; Athaide O. II, «Os dois compadres», 123; Câmara Cascudo, «Os compadres corcundas», Contos, 31; Espinosa I \#175, «Los dos hermanos»; Grimm \# 183 «The Gift of the Wee Folk»; Ramón A. Laval, «Salir con su domingo siete», Cuentos populares en Chile (Santiago: Cervantes, 1923) 101; Ricardo Palma, «Salir con un domingo siete», Tradiciones Peruanas: Obras completas (Madrid: Aguilar, 1961) 1186; Pino Saavedra II \#91, «La piedra misteriosa de los doce bandidos»; Rael \#255, «Los jorobados», \#256 «El jorobado»; Ramón y Rivera, «Domingo siete», 229; Riera Pinilla \#46, «Las brujas y el diablo», \#47, «Los siete ladrones». Las versiones de Palma, Pino Saavedra, Ramón y Rivera y Riera Pinilla no aparecen en los índices publicados hasta el momento. 
De las trece versiones consultadas ${ }^{25}$, Andrade \#144, Espinosa \#175 y Pino Saavedra \#91 incluyen estos elementos (con variaciones) pero sólo en la de Carmen Lyra es la mujer la instigadora de la codicia del marido.

Los elementos 1, 7 y 15 (exceptuando los detalles), aparecen únicamente en las versiones de Portugal (Braga), Brasil (Câmara Cascudo), Chile (Laval), Perú (Palma) y las de Nuevo México y Colorado (Rael). Sólo en Carmen Lyra se trata de un bocio.

La cantilena (elementos 4, 3 y 13) es parte importante de la trama, ya que de ella depende el desenlace final tanto en las versiones mencionadas en el párrafo anterior como en la venezolana (Ramón y Rivera) y la panameña \#46 (Riera Pinilla).

El hombre pobre recibe también dinero (elemento 8) en las versiones de Câmara Cascudo, Laval, Ramón y Rivera y Rael \#256.

Los elementos 2, 5, 6, 11 y 14 son exclusivos de Carmen Lyra. En cuanto al final (16), hay gran variedad. La panameña \#46 dice que el hombre rico murióa los tres días de la paliza que le dieron las brujas. La venezolana termina diciendo que: "De ahí (el título) viene el nombre de 'Domingo Siete'. Quiere decir un intruso que viene a meterse donde no cabe" (Ramón y Rivera, 237). En la brasileña de Câmara Cascudo, «O povo esqui sito», equivalente a «The Wee Folks» de Grimm, furioso con el compadre rico le grita:

Quem lhe mandou meter-se onde não e chamado seu corcunda besta? Você não sabe que gente encantada não quer saber de sexta-feira, dia em que morreu o filho do Alto; sábado, dia em que morreu o filho do Pecado, e domingo, dia em que ressuscitou quem nunca morre? Pois fique sabendo! $\mathrm{E}$ para que não se esqueça da liçao, leve a corcunda que deixaram aqui é sumase da minha vista sinão acabo com seu couro! (...). E assim viveu o resto de sua vida, rico, mas com duas corcundas, una adeante e outra atras, para não ser ambicioso ${ }^{26}$.

26. Câmara Cascudo, 33. 
Ricardo Palma interpreta el «Domingo siete» diciendo que "Esto sería verdad como un templo, pero no caía en verso" (1187) y como "las brujas se pegan mucho de la medida y de la rima" (1187), castigaron "al entrometido (...) para escarmiento de poetas chirles" (1187). Luego para ampliar más, añade:

cuando cae en siete el primer domingo del mes, dice el pueblo: "¡Con qué domingo siete nos saldrá este mes!"; que es como vivir prevenido a que no le coja a uno de nuevo un cataclismo o una crisis ministerial, de esas que entre nosotros concluyen con algún domingo siete: esto es, de la forma menos prevista (1187).

Ramón Laval también da una explicación del refrán en nota aparte: "De este cuento procede la frase familiar tan común en Chile y en otros países hispanoamericanos, 'Salir con su domingo siete', que se aplica a los que dicen o hacen cosas fuera de razón" 27 . Carmen Lyra no interpreta ni discute el título dentro o fuera del cuento ${ }^{28}$.

«La flor del olivan» (112-117)

Este cuento es una mezcla de dos cuentos-tipo: 551 y 780.

Unos hijos van en busca de un remedio para curar a su padre (el número es generalmente tres). Sólo el menor tiene éxito ayudado por un enano, un águila o un objeto mágico: Aäme-Thompson y Hansen 551, «The Sons on a Quest for a Wonderful Remedy.» El hermano (o hermana) menor es asesinado por sus otros hermanos (generalmente dos) y enterrado. De sus huesos un pastor hace una flauta que revela el secreto.

27. Laval, Cuentos, 289. Membreño atribuye este dicho a que "el domingo nunca ha sido el séptimo día de la semana" y, por tanto, es lógico decir que domingo siete significa "despropósito, disparate", Hondureñismos, 3a. ed, 70.

28. Sin embargo, Jaime Homero Arjona y Carlos Vázquez Arjona, edits., dicen en su antología Cuentos de las Españas (New York: Scribner's Sons, 1943) 23, refiriéndose a la versión de Carmen Lyra: "This story like «El alacrán de Fray Gómez» explains a phrase, in this case, 'Salir con un domingo siete,' which means 'to speak out of turn'." 
En las diferentes versiones el crimen se revela de distintas maneras: a) un instrumento (arpa, flauta, etc.) hecho de los huesos, o b) de un árbol nacido de la sepultura: Aäme-Thompson, Boggs, Hansen, cuento-tipo 780 .

La versión de Carmen Lyra presenta los elementos de esta manera:

1. Un rey ciego tiene tres hijos.

2. Ningún médico ha sabido curarlo. Un caminante desconocido le aconseja que se lave los ojos con agua de la Flor del Olivar. Sin más explicaciones sigue su camino y desaparece.

3. El rey ofrece su corona al hijo que le traiga la flor.

4. El hijo mayor, y luego el segundo, salen en su busca bien provistos de dinero y comestibles.

5. Tropiezan con una mujer que está lavando en un río, y cuyo niño, extremadamente delgado, llora desconsoladamente. La mujer les pide algo de comer para el hijo. El mayor contesta: "iQue coma rayos, que coma centellas ese lloretas! Todo lo que va en las alforjas es para mí" (113). El segundo dice: "Yo no ando alimentando hambrientos" (114).

6. Nadie les da razón de la Flor. Se meten a una casa de juego y "juegan hasta los calzones" (114).

7. El tercer hijo, casi un niño, se compadece de la pordiosera. Hace "sopas" de leche y pan y él mismo se las da al niño en su tacita de plata, luego lo duerme y lo acuesta bajo un árbol.

8. La mujer, que es la Virgen, le pregunta la razón de su viaje y luego le indica que la Flor está debajo de una piedra al lado del niño.

9. El hermano menor se encuentra con los mayores, quienes lo reciben "con mucha labia" (115), lo invitan a comer, lo embriagan, luego lo matan y lo entierran en un campo. Los dedos quedan fuera de la tierra.

10. El rey se cura con la Flor que le llevan los dos hijos y les promete el reino a su muerte. 
11. Los dedos del príncipe retoñan y nace un macizo de cañas. Un pastor corta una de las cañas para hacer una flauta y, al soplarla, se sorprende al oír la siguiente canción: "No me toques, pastorcito,/ni me dejes de tocar;/ que mis hermanos me mataron/ por la Flordel Olivar" (116).

12. El pastor obtiene popularidad con el instrumento maravilloso. Llega su fama a oídos del rey, quien lo hace comparecer ante sí. La voz le recuerda a su hijo menor. Al tocarla él mismo, se repite la canción cambiando "pastorcito" por "padre mío". Lo mismo sucede al tocarla la reina. Cuando es el segundo hijo el que toca, la flauta se lamenta: "No me toques, hermano mío,/ ni me dejes de tocar,/ que aunque tú no me mataste $/$ me ayudaste a enterrar" (117). Al tocarla el mayor, se vuelve agresiva: "No me toques, perro ingrato, $/$ ni me dejes de tocar, que tú fuiste el que me mataste,/porla Flor del Olivar" (117).

13. El rey los manda a un calabozo y "él y la reina se quedaron inconsolables" (117).

De las cuarenta y dos versiones consultadas ${ }^{29}$, Grimm \#47, «The Water of Life,» pertenece exclusivamente al cuento-tipo 551. El resto desarrolla la trama alrededor de los elementos 9, 11 y 12 de Carmen Lyra (cuento-tipo 780), formando una especie de tema con variaciones que armonizan con los elementos 1,2 y 3 :

29. Andrade \#41, «La flor del calbolial», \#42, «La flor de Belian, \#43, «Lo tre hermano», \#44, «El agua de la vida», \#45, «Ei cuento dei gigante», \#125, «Ei cuento dei jigo», \#126, «El cuento del higo», \#127, «El higo», \#128, «La hija enterrada», \#129 «Los tres higos»; Athaide O. I, «A flor do Liro-Lan», 460; Fernán Caballero, «El lirio azul», Cuentos, adivinanzas y refranes populares (Madrid: Sáenz de Jubera Hermanos, eds, s.f.) 39-40; Espinosa \#152, «Las tres bolitas de oro», Cuentos I; Grimm \#28, «The Singing Bones», \#47 «The Juniper», \#97, «The Water of Life»; Ramon A. Laval, «Los tres lirios», Contribución al folklore de Carahué (Santiago de Chile: Universitaria, 1920) II, 20; Mason-Espinosa, «La flor del Olivan, JAF XXXVIII (1925) 549, siete versiones y nueve versiones de «La mata de ají», 557; Rael \#91, «Los tres hermanos», \#92 «Las tres bolitas de oro». Otras versiones encontradas en el transcurso de esta investigación: Câmara Cascudo, «A menina enterrada viva», Contos, 452-453; Carvalho Neto \#41, «El rey ciego»; Trinidade Coelho, «O conto das tres maçazinhas de ouro», Os meus amores, contos e baladas (14 ed., Lisboa: Portugalia, 1962) 339; Pino Saavedra II, \#104, «La flor del lirolay»; Riera Pinilla \#43, «La flor del lilolá», \#44, «Los tres hermanos», Lecturas para un niño venezolano (Caracas: Fundación Mendoza, 1953) 26; Romero, «A raposinha», Contos, 80-84. 
Oh dear shepherd,/ You are blowing on my bone./ My brother slew me,/Buried me underthe bridge,/Because of the wild boar,/ To win the King's daughter ${ }^{30}$.

My mother, she killed me $/$ My father, he ate me $/$ My sister Marlene/ Collected all my bones,/ Tied them up in a silk cloth, Laid them under the juniper, / Tweet, tweet, what a beautiful bird I am! $!^{31}$.

Toca, toca bon pastor,/ Y no ennamenes/Por la flor del lliri blau/ Man mort en riu de arenas ${ }^{32}$.

En la versión portuguesa (T. Coelho), después de que han tocado la flauta el pastor, un carbonero, un herrero y el padre, lo hace el hermano: "Toca, toca, meu irmao/ Que tu mesmo me mataste,/ P'ra amor de tres maçazinhas/ E ao cabo não nas levaste!" (339). En «Las tres bolitas de oro» (Espinosa I) dice: "Segadores que vais a segar, no seguéis mi lindo pelo/ que la tuna de mi madre me enterró por higo y medio" (371) y las brasileñas de Câmara Cascudo y Romero: "Capineiro de meu pai/Não me cortes os cabelos .../Minha mâe me penteou, / Minha madrastra me enterrou,/Pelo figo da figueira/ Que o passarinho picou/ /Cho passarinho!"33.

Como se puede apreciar en las citas anteriores, no es siempre la posesión del remedio maravilloso (flor, agua, etc.) la causa del crimen. En Grimm \#97 y Andrade \#45 es envidia por la victoria sobre una fiera o gigante, o por la posesión de unas bolitas de oro como en Espinosa

30. Grimm \#28, 109.

31. Grimm, «The Junipen», 171. En realidad, este cuento pertenece al tipo 720 debido a otros elementos que contiene.

32. Caballero, «El lirio azul», 40.

33. Páginas 453 y 120 respectivamente. El último verso se omite en la versión de Romero. Pedro Henríquez Ureña y Bertram D. Wolfe recogieron este otro verso: "Pastorcito no me pites/ni me vuelvas a pitar./ Mis hermanos me han matado/ por la flor del Olilán", Vicente T. Mendoza, El romancero español y el corrido mexicano (México: Universidad Nacional Autónoma, 1939) 384. 
\#152 y Rael \#91 y \#92. En «The Juniper» es el odio el que mueve a la madrastra hasta el punto de hacer con el hijastro un pastel para dárselo al padre. En las versiones de Andrade \#125 a \#129, la serie «La mata de ají», Câmara Cascudo, Romero, Coelho y Wheeler \#137 es por causa de una fruta (higo, aguacate, manzana) que hace falta.

Sólo en unas cuantas versiones, los hermanos o las hermanas pierden el derecho al objeto maravilloso (elemento 5 en Carmen Lyra), a causa de las respuestas dadas a la anciana, pordiosera o la Virgen, según sea el caso. Por ejemplo, en Espinosa I \#152, cuando le piden a la hija parte del almuerzo que lleva para el padre, contesta: "¡Vaya usted a ganarlo como mi padre y mi madre!" (368). En otra versión (Mason-Espinosa) la respuesta es que el pan lo habían comprado para comérselo y no para darlo; en otra niegan que se pueda comer y dicen que son piedras (en las que se convierte en efecto), y aun otra dice solamente, "iVaya usted con Dios!" (549), sin compartir lo que llevan.

El final de la versión de Carmen Lyra es de gran realismo (elemento 13). El cuerpo enterrado, muerto está y no revive con remedios mágicos(Pino Saavedra,Laval), ni lo arrebata la Virgen para llevárselo al cielo (Coelho), ni lo desentierran vivo (Andrade \#42, Cascudo, Romero, Espinosa \#152, cinco de las versiones MasonEspinosa y las dos de Riera Pinilla). En la versión valenciana (Caballero) el héroe "vivió y reinó muchos años, pero siempre sin un dedo" (40). Muy cómica es la versión ecuatoriana (Carvalho), pues el rey, que estaba paseándose, oye que le dicen: "Sácame de aquí, mis hermanos me tienen por muerto, pero me hallo sano y salvo en un tubo de cemento" (229).

Los castigos sufridos por los culpables varían en las distintas versiones: mueren desgarrados por unas fieras, se hunden con el barco en que huyen, los mandan matar, quemar, encerrar en un sótano o dan a comer su carne cocida. En Carmen Lyra, el rey castiga a los culpables, pero justa y humanamente, enviándolos a un calabozo. Y como dice la autora, a este y a la reina no les queda sino lamentar su desgracia el resto de su vida. 
«El pájaro dulce encanto» (129-139)

En este cuento, como en «La flor del olivan», la búsqueda de una cura maravillosa por parte de tres hermanos sirve de motivación a la acción. La cura para el padre ciego es un pájaro. No sólo consigue el héroe el pájaro, sino que también un caballo que vuela y una princesa a quien libra de las garras de un gigante, con la que se casa el joven.

Pertenece al cuento-tipo 551, «The Sons on a Quest for a Wonderful Remedy,» mas unos cuantos elementos corresponden al 550, «The Bird, the Horse and the Princess» (Aärne-Thompson y Hansen). Los elementos de estos cuentos-tipo son los siguientes:

I Object of the Quest. a) [No rige]; b) a sick [blind] king orders a quest for a magic remedy.

II The Three Sons. Three sons of the king go on the quest. The two elder are unkind to animals (old woman, dwarfs) that they meet, and they fail; but the third is kind and receives the help of the animals.

III Success of the Quest (coincide con el 550 con ciertas variaciones): a) the hero reaches the tree of the golden bird but is to receive the bird only after he undertakes further quests. b) On these, he receives a magic horse and a princess, and he takes them home along with the magic bird.

The Treacherous Brothers: a)The hero's elderbrothers rob him and throw him into a well, or b) wolf's den.c) He is helped out and his goods restored by his helpful fox, or d) by the wolf, to which he feeds meat.

Los elementos de «El pájaro dulce encanto» son:

1. Un rey ciego promete el reino al hijo que le traiga el pájaro dulce encanto, cuya cola ha de curarlo, según una bruja curandera.

2. El hijo mayor parte por la mañana, el segundo al medio día y el menor por la tarde. 
3. Se encuentran con un grupode gente que contempla un muerto tirado en las gradas de una iglesia y de cuyo entierro nadie quiere encargarse. Los dos príncipes mayores siguen su camino pero el tercero se conduele, busca un buen ataúd, un cura que cante el responso y ayuda a cavar la sepultura.

4. Al caer la noche una luz se le aproxima al joven quien, lleno de sobresalto le pregunta: "De parte de Dios todopoderoso, di, ¿quién eres?" (131). Una voz explica que se trata del alma del hombre a quien ayudó enterrar, por lo cual lo ayudará a encontrar lo que busca ${ }^{34}$.

5. A la medianoche (el alma sólo puede ayudarlo de noche), llegan a un palacio: entran en el jardín y luego en un salón de cristal con rosales en macetas de oro. Del centro cuelga una lujosa jaula donde un pájaro blanco con copete y patas color coral entona un canto que más parece que proviene de una orquesta. El príncipe, como sobrecogido por un hechizo, permanece estático, pero se rehace al mando de la voz que le ordena traer mesas y sillas para alcanzar la jaula. La improvisada torre se derrumba con gran estruendo y atrae a los guardias y al mismo rey, que ordena que se le encarcele.

6. Días después, el rey le promete la libertad y el pájaro si le consigue un caballo que él aprecia mucho, a lo cual se compromete el príncipe por conse jo de la luz.

7. Llegan al "potrero", donde un gigante guarda el magnífico caballo. Por conse jo de la luz, espera el príncipe a que se duerma el gigante (lo que será cuando ambos ojos del gigante queden totalmente abiertos después de estar cerrados). Al acercarse el príncipe al caballo, este grita: "¡Amo, amo, que me roban!" (134). El gigante se despierta pero no ve a nadie. La segunda vez que sucede lo mismo el gigante amenaza al caballo que permanece callado cuando el príncipe se le

34. Se debía tener mucha precaución ante un aparecido, pues bien se podía tratar de un demonio. Era costumbre pedir identificación-. De ahí que Horacio en Hamlet (I,i) empiece con esas palabras al dirigirse a la aparición de su padre muerto: "What art thou that usurp'st this time of night, / Together with the majesty of buried Denmark / Did sometimes march? by heaven I charge thee, speak!" 
acerca por tercera vez. El príncipe lo monta y, advertido por la luz, aprieta una tuerca que el caballo tiene y salen volando, pero lo hace bajar antes de llegar al palacio del rey.

8. El rey le pide ahora que le traiga a su hija robada por el mismo gigante.

9. Regresa con el caballo y espera que el gigante esté embriagado de vino y le hace señas a la princesa, que inmediatamente lo sigue.

10. Por tercera vez se niega el rey a darle el pájaro. El príncipe, siempre por consejo de la luz, le pide le permita dar una vuelta en el caballo alrededor de la bien resguardada plaza con el pájaro y la princesa, a lo cual el rey accede.

11. El príncipe aprieta la tuerca y el caballo sale volando. No se detienen sino hasta llegar al país del príncipe, donde este hace bajar al caballo.

12. Pasan por donde los hermanos estaban "engringolados" en una fiesta, quienes al ver su éxito se llenan de envidia, lo duermen a él y a la princesa con un narcótico y lo arrojan por un precipicio.

13. Se presentan ante el padre con pájaro, caballo y princesa. Pero esta no volvió a hablar y el pájaro ni cantó más, ni curó al rey.

14. El príncipe, que no había muerto, sino que había quedado cogido por unas ramas (por manejos de la luz, según informa la narradora), fue rescatado por unos carreteros.

15. Vuelve al palacio, pero el rey no quiere tener nada que ver con él debido a las calumnias de sus hermanos. Los carreteros y la princesa sirven de testigos, la cola del pájaro le devuelve la vista al rey cuando el príncipe se la pasa por los ojos, demostrando su inocencia.

16. El príncipe perdona a los hermanos y se casa con la princesa.

17. La luz se despide de él diciéndole: "Ya cumplí, ya te demostré mi gratitud. Adiós y ahora hasta que nos volvamos a ver en la otra vida" (139).

"lil pájaro dulce encanto» concuerda exactamente con el ele-

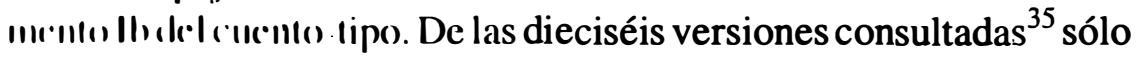


en la segoviana (Espinosa \#143), las chilenas (Pino S. \#60 y Laval) y en la neomexicana (Mason) es la ceguera o enfermedad del padre el motivo que mueve a los hermanos a buscar el remedio, que en los de Laval y Mason es únicamente el pájaro.

El animal, mujer o enano del cuento-tipo (II), se sustituye en «El pájaro dulce encanto» por el muerto, cuya alma agradecida ayuda al héroe a conseguir lo que busca (elementos 3 y 4). Esta interesante variación se encuentra también en la versión chilena de Laval, donde se presenta como un "negrito", la puertorriqueña (Andrade), donde el ánima toma la forma de una zorra, una raposa en la segoviana (nótese la relación con IV c. y b. del cuento-tipo), un coyotillo en Rael \#98 y \#99, así como en \#118 de Wheeler, mientras que en la \#117 es un cuervo. Sólo en dos es simplemente una sombra (Wheeler\#116 y Rael \#99). En las demás versiones donde aparece este elemento, el héroe es bondadoso con los animales, un viejito o un enano, etc. En Grimm \#57, la zorra solicita que se le corten las patas y la cabeza, convirtiéndose entonces en el hermano de la princesa rescatada.

Laforma y naturaleza de las tareas impuestas al héroe para ganar el pájaro (IIa) y el truco que usa para quedarse con él, con la dama y el caballo (IIIb), son casi exclusivos de la versión de Carmen Lyra (elementos 6 a 11). Sólo en la chilena, «El pájaro malverde», el príncipe se escapa en forma parecida, haciendo volar el caballo y llevándose a la princesa y el pájaro. Estas dos versiones son las únicas en que los of ensores no son castigados severamente a petición del ofendido.

35. Andrade \# 180, «El rey ciego»; Espinosa I \#143, «Las tres maravillas del mundo»; Grimm \#57, «The Golden Bird»; Ramón A. Laval, «El pájaro malverde», Carahué II, 39; Alden J. Mason, «Four Mexican-Spanish Fairy Tales from Azqueltán, Jalisco»; "Cuento del pájaro del dulce canto», JAF, XXV (1912), 194; Rael I, \#199, «El pá jaro de colores», II, \#98, «Bernardo», \#99, «Don Juanito»; Romero, "A fonte das tres comadres», Contos, 179-185; Wheeler \#116, «La niña robada», \#117, «Una obra de misericordia», \#118, «El coyotito y la pluma del pájaro Cu». Aportaciones de este estudio: Carvalho Neto \#26, «El caballito mágico», \#27, «El caballito de cien mil colores», Cuentos folklóricos del Ecuador, Pino Saavedra I, \#60, «La mulita manca», \#62, «Los tres hermanos»; Riera Pinilla \#10, «El pájaro grifo». 
Algunas de las complejidades de otras versiones no aparecen en la de Carmen Lyra: no hay pájaro o pluma de oro que inspire codicia, ni frutas robadas del árbol de un rey, ni más de un remedio u objeto codiciado, ni complicaciones con varios reyes, princesas o damas, ni muertos encarnados en animales, etc. Tampoco desobedece el héroe los consejos del ayudante sobrenatural, con la consecuente pérdida de los objetos para recobrarlos de nuevo cuando por fin hace lo que le han indicado.

Se puede concluir que aunque «El pájaro dulce encanto» está dentro de la tradición del cuento-tipo 551, y parte del 550, el conjunto total de esos elementos presenta un desarrollo propio: un mínimo de personajes, una trama simplificada sin hechos inesperados ni exageradamente espectaculares y un final donde predominan la gratitud y el perdón en vez de la venganza.

«Escomponte perinola» (45-61)

Pertenece al grupo de cuentos cuya trama se desarrolla alrededor de uno, dos o tres objetos adquiridos por el protagonista en circunstancias extraordinarias, objetos que luego pierde o le roban y vuelve a recobrar.

En Aäme-Thompson y Hansen aparece clasificado como cuento-tipo 563: «The Table, the Ass and the Stick,» analizado en la forma siguiente:

I The Magic Objects. a) A poor man receives three magic objects, b) a table or sack that supplies itself with food, c) a golddropping ass, d) and a cudgel or e) a sack containing a mannikin that beats an enemy until called off by its owner.

II The Objects Stolen and Recovered. a) The first two objects are stolen by the host of an inn, b) by the hero's brother, c) or by a neighbor. d) By means of the cudgel or sack the other objects are recovered. 
«Escomponte perinola» presenta sus elementos así:

1. Este es un hombre a quien apodan "Juan Cacho", debido a la mala suerte que le aqueja: una mujer de muy mal genio, unos hijos enfermizos y malcriados y, aunque esté dispuesto a hacer cualquier clase de trabajo, pocas veces consigue ganar lo suficiente para mantener a su numerosa familia, lo cual aumenta el malhumor de la mujer.

2. Aburrido de su situación, decide un día dejar el hogar para "ir a rodar tierras" (45).

3. Cansado y hambriento, se dispone a comer lo único que lleva consigo, "un diez de pan y quince de salchichón" (45), cuando se da cuenta de que un viejito de lastimero aspecto lo está mirando con ojos hambrientos.

4. Juan Cacho comparte con él sus escasos comestibles y luego su tosca cama de hojas.

5. Al despertar, hace mucho frío y Juan Cacho piensa en lo agradable que sería "un jarro de café caliente" (46). Su compañero, como si le leyera el pensamiento, le pregunta si le gustaría tomar una taza de café al mismo tiempo que saca del bolsillo una servilleta que, por lo blanca, contrasta con lo sucio de los trapos con que se cubre el viejo, y se la entrega.

6. Juan Cacho reflexiona que tal cosa no podría servirle para aplacar el hambre pero el viejo, adivinando de nuevo su pensamiento, le explica que se trata de una servilleta de virtud a la cual se hizo merecedor por su buen corazón. En ese momento Juan Cacho se da cuenta de que se trata de "TATICA DIOS en persona" (47).

7. Sigue las instrucciones que le da el Señor, extiende la servilleta sobre el suelo pidiéndole que le dé de comer "por la virtud que Dios le dio" y, efectivamente, aparece sobre ella un suculento desayuno.

8. Más tarde, Juan Cacho repite el inusitado hecho y decide volverse al hogar. Se detiene en un sesteo, donde se encuentran varios viajeros tomando café, y los invita a darse un banquete. 
9. El dueño del sesteo que "era lo que se llama un hombre angurriento, de los que no pueden ver bocado en boca ajena, le echó el ojo" (49) a la servilleta $\mathrm{y}$, tan pronto como se durmió Juan, se la cambió por otra.

10. Vuelve a su casa muy contento y se apresura a extender la servilleta delante de la mujer y los hijos, después de "haber tirado al patio" los pocos "guineos" (50) que tenían de comida. Perola servilleta no responde a sus palabras y él tiene que salir de la casa peor parado que antes.

11. Se dirige al mismo lugar donde había encontrado a Tatica Dios para darle cuenta de lo sucedido. Este aparece con "un borriquito de diestro" (51) que da monedas de oro a la orden de: "por la virtud que Dios te dio, reparame plata" (52).

12. Juan Cacho coge de nuevo camino de su casa, pasando primero por el sesteo, donde hace una demostración con la subsecuente substitución por parte del dueño.

13. Cuando llega a su casa, en vez de monedas, el burro no hace sino ensuciar la única cobija que tenían.

14. Juan Cacho sale de nuevo camino al sitio del encuentro con el Señor, preguntándose si no habría querido burlarse de él, pero concluye que "El Señor no es de broma y menos con un triste como yo" (54).

15. Cuando Nuestro Señor se presenta, recrimina a Juan por su falta de carácter al no hacerse respetar de su mujer y sus hijos, por su falta de "malicia" y su demasiada confianza en todo el mundo.

16. Le presenta luego una perinola que a la voz de "escomponte perinola", sale del saco que la contiene y comienza "a arriarle a Juan sin misericordia" (56).

17. A la voz de "componte perinola", esta vuelve al saco.

18. El Señor prosigue entonces a explicarle que la paliza fue una locivion para que aprendiera a "no dejarse", pues el ser demasiado lincili) (onntribuye a (juc el egoísmo "se extienda como una mata de

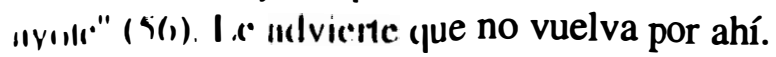


19. Juan le da la razón y se promete pedir cuentas al dueño del sesteo y a su mujer e hijos.

20. Ya en el sesteo, le dice al dueño que satisfará su curiosidad acerca de lo que lleva en el saco cuando estén donde nadie les oiga, y da órdenes de que ninguna persona se acerque, oigan lo que oigan.

21. Así se hace, y se encierran en un cuarto, donde la perinola le da al dueño una gran garroteada.

22. Le son devueltos la servilleta y el burro, y se dirige a su casa, donde somete a esposa e hijos al mismo tratamiento. La paliza no cesó hasta que no prometieron comportarse con él como era debido.

23. Los hijos se volvieron muy educados, pues "puso colgando en el salón y medio a medio, el saco de la perinola, con una pizquita de fuera, para que todo el mundo viera que allí estaba quien todo lo arreglaba" (61). El cuento termina con la advertencia de que todo eso sucedió hace muchísimos años.

Los elementos comunes a las versiones consultadas ${ }^{36}$, con ligeras variaciones de circunstancias y personaje, son 7, 9 y 10 (con algunas excepciones), 11,12,16,21 y 22 , o sea aquellos que tienen que ver exclusivamente con la pérdida y la recuperación de los objetos perdidos. En Wheeler, San Pedro le da una servilleta y un palo a una viejita que había subido al cielo a pedir que "le den pa pasar porque no tiene con que mantenerse" (503). También en Andrade \#142 llega al cielo un "haragán" y Dios le da un mantelito, un burro y un garrote. El protagonista de la versión chilena (Laval) sube al cielo y recibe los tres objetos. En Carvalho Neto \#34 un pobre pide limosna y en un convento le dan un mantelito y un palo. La versión \#177 (Espinosa) no indica por

36. Andrade \#141, «El cuento del sastre», \#142, «El jaragán», \#143, «La chiva y el palo mágico»; Caballero, Cuentosy poesías populares, 75; Espinosa I \#177, «La princesa que nunca se reía»; Grimm \#36, «Table-Be-Set, the Golden Donkey, and Cudgel-Come-Out-of-the Bag»; MasonEspinosa, «Puerto Rican Folklore: Juan y los objetos mágicos», JAF, XXXV (1922) 2, \#57a, \#57b, \#57c, \#57d, \#57e; Rael II, \#127, «El papalotito»; Wheeler \#182, «San Pedro y la vieja». Aportaciones de este estudio: Carvalho Neto \#33, «Una familia pobre», \#34, «El mantelito»; Laval, «Los palitos de virtud», Carahué, II, 205. 
qué la criada de una posada posee y da los tres objetos a Juanillo el "Simplón", que termina casándose con la princesa, gracias a su ingenio. (Es, pues, un cuento de la serie picaresca de «Juan el Tonto»). En «Juan y los objetos mágicos», \#57, Juan Bobo halla a un viejo a quien le dice que va "a buscar dinero donde está Dios" (2) y este, sin más razones, le da una cajita y un bastón con las consabidas dotes. En el \#57b, recibe los dos objetos mágicos de un rey, en pago de un mes de trabajo. Algo parecido se dice en \#57c, mientras en \#57d y \#57e el agente es el viento personificado. En la versión de Fernán Caballero, un hombre, a punto de ahorcarse después de haber despilfarrado su hacienda, recibe deun duendecillo una bolsa que nunca se vacía, luego un mantel y por último una porra (garrote).

Sólo la versión de Carmen Lyra presenta los elementos 3, 4, 5 y 6, de modo que sólo aquí los tres objetos, que poseen poderes divinos y no mágicos, son otorgados en pago por un acto de caridad. De ahíque la fórmula para que la servilleta y el burro cumplan su cometido sea "por la virtud que Dios te dio" (52) (esta fórmula se usa también en Carvalho Neto \#34 pero sin previa motivación). En Espinosa \#177, Mason-Espinosa \#57c, Rael \#217 y Wheeler \#502 se usan exclusivamente "descomponte" "componte". Las demás no tienen fórmula especial.

«La mica» (62-76)

Este cuento es, esencialmente, una versión del cuento-tipo 402 de Aäme-Thompson y Hansen, «The Mouse (Cat, Frog, etc.) as bride»: "The youngest of three brothers succeeds best in the quest set by his father. He brings the best cloth, the most beautiful bride, etc. The mouse (cat), who has helped him, changes herself into a beautiful maiden".

«La mica» se desarrolla de la manera siguiente:

1. Un rey tiene tres hijos y promete el trono al que venga casado con la princesa "más hábil y bonita". 
2. En realidad, el rey considera que sus hijos están demasiado mimados por la reina madre y desea alejarlos para que se hagan hombres.

3. Para que la reina no sospeche su plan, sale primero el mayor, luego el segundo y, por último, el menor.

4. Los tres príncipes llegan sucesivamente a la misma.casita en medio de un potrero, donde piden posada.

5. Una vieja que «daba de latigazos a una miquita" (63), contesta a los solicitantes que su casa no es hotel, pero pueden pasar la noche en la "banca", en el "corredor".

6. A la medianoche los despierta la mica suplicándoles que se casen con ella pues sólo así podrá salir de los malos tratos de la vieja, y les muestra su cuerpo llagado.

7. Sólo el menor de los príncipes tuvo piedad de la pobre mica. Amenazó a la vieja con el mismo palo si no cesaba de golpear al animal. Y más tarde no pudo resistir los sollozos y la tristeza que mostraba "aquella carita peluda" (65), por donde "corrían las lágrimas" (65) y, "como siempre había sido de ímpetus" (65), accedió a sus súplicas.

8. En ese momento "retumbó la casa y entre un humarasco apareció la bruja que gritaba: ' $i Y$ ahora cargá con tu mica para toda la vida!'" Y el príncipe se sintió atado a una cadena.

9. Conforme caminaba con su mica, reflexionaba sobre la estupidez que había cometido, preguntándose lo que dirían sus padres.

10. La mica, como adivinando, sugiere que se vayan a una montaña a vivir en una casita pobre, pero limpia.

11. Al cabo de un año, aunque él no le había dicho nada, la mica lo insta a que vaya a encontrarse con sus hermanos en el lugar convenido, lo que hace con desgano.

12. Al preguntarle los hermanos, que se habían casado muy bien, por su esposa, hace tal panegírico de ella, que sienten envidia.

13. El rey encarga a cada nuera, para él y la reina, una camisa «tan fina que un muchachito de pocos meses la pueda guardar en su mano» (68). Les da un mes de plazo. 
14. El día sè llegó, y la mica sin hacer nada, pero le ensilló el caballo y lo instó a que partiera.

15. Le da dos "semillas de tacaco", advirtiéndole que eran las camisas. Si así no fuera, se podría considerar libre de ella.

16. Al entregar las semillas al rey, los hermanos se ríen de él, y el rey, enojado, las destripa dejando ver en su interior "una camisa de tela tan fina que una hoja de rosa se vería ordinaria a la par" y de gran blancura. Los botones eran piedras preciosas y las costuras no se podían ver ni buscándolas con lente (69).

17. El rey declara estar satisf echo de todos los hijos, y encarga un plato para determinar cuál cocina mejor. El plazo es de quince días.

18. El día fijado, la mica le da al príncipe una canasta con un "ayote" cocido.

19. Cuando ve a sus hermanos seguidos de criados cargados de bandejas de oro y plata con manjares exquisitos, no puede evitar el sentirse avergonzado de lo que lleva.

20. Cuando el rey recibe el ayote del hijo menor, lo revienta contra la pared. En ese instante salieron volando de él palomitas blancas, con unas canastitas de oro en el pico, llenas de "manjares tan deliciosos como los que se deben comer en el cielo en la mesa de Nuestro Señor" (70).

21. El rey pide entonces una vaquita que se pueda ordeñar en la mesa. Les da ocho días de plazo.

22. Esta vez, la mica le entregó al príncipe "un canuto decaña de bambú" (71).

23. Como las veces anteriores los hermanos, que llevaban unas vaquitas enanas, se burlaron de él. Pero cuando el rey preguntó por la suya, el príncipe abrió el canuto y "va saliendo una vaquita alazana con unas campanitas de plata y cachitos y casquitos de oro. Las teticas parecían botoncitos de rosa en miniatura. Se fue a colocar frente al rey y sobre su taza, como para que la ordeñara" (71).

24. La última prueba ha de ser las esposas mismas, que han de presentarse el domingo siguiente. 
25. El príncipe está seguro de no pasar esta prueba, pero de todos modos compra tela, perfume y otras prendas femeninas.

26. Durante aquella semana, la mica no hizo sino las labores de costumbre y "maromas en la solera" (72). El príncipe acongojado se decía que "su esposa no era sino una pobre mica" (72).

27. Se llega el domingo y la mona insiste en ir en carreta y manda al príncipe que salga adelante.

28. Las hermosas esposas de los hermanos iban en carrozas de cuatro caballos, y los príncipes se sienten humillados al ver que la cuñada viene como "una compirusa" en carreta. El rey cree que su hijo menor se ha vuelto loco, pero ordena que dejen pasar la carreta.

29. El príncipe se sentía avergonzado y temeroso de la reacción de la concurrencia, perocon gran sorpresa suya, en vez de la mica salió una bellísima princesa lujosamente vestida, quien tomándolo de la mano, le pidió graciosamente la presentara a sus padres.

30. Al empezar el baile la princesa, que durante el banquete había guardado en su seno pedacitos de las viandas servidas, se sacudió el traje haciendo rodar perlas, rubíes y flores de oro. Las cuñadas, que la habían imitado, se pusieron en ridículo al dejar caer las viandas mismas.

31. El rey escoge como sucesor al hijo menor, pero la princesa declara que mejor se reparta el reino entre los hermanos mayores, porque ella es la hija del rey de Francia, cuyo trono ha de ocupar con su esposo.

32. Ya camino de Francia le explica al príncipe cómo había sido convertida en mica por venganza de una bruja, por no querer su padre casarse con ella.

El elemento 1 aparece en todas las versiones consultadas ${ }^{37}$ menos «A princesa gia» (Câmara Cascudo), «A sapa casada» (Romero),

37. Andrade \#47, «La novia del príncipe errante», \#257, «La ranita Pere»; Athaide I, «A macaca», p. 25; Câmara Cascudo, «A princesa gia», Contos, 68; Espinosa I, \#145, «La princesa mona»; Espinosa, Castilla, \#46, «La mona encantada»; Grimm\#63, «The Three Feathers», \#106, «The 
«La ranita» (Rael \#183), «Jeremillo» (Wheeler) y «The Envious Sisters» (Parsons), donde los hijos de una pareja pobre deben correr mundo para ganarse la vida. «The Poor Miller's Servant and the Cat» (Grimm \#106) trata de un molinero ya viejo y sus tres aprendices; el que le traiga el mejor caballo será el poseedor de su molino, encargándose también de mantenerlo hasta su muerte. En «The Frog-Woman» (Mason), no hay intervención del rey. El príncipe, aun sin compromiso, lleva a su burro a beber a un lago, donde se encuentra con la "mu jer-rana".

El verdadero motivo, por parte del rey, del viaje de los príncipes y la forma en que lo ejecutan, es exclusivo de la versión de Carmen Lyra (elementos 2 y 3). En Grimm \#63, Riera Pinilla \#19 y Pino Saavedra\#39, los príncipes siguen la dirección tomada por tres plumas o flechas, o se casan con quien se encuentra en el lugar donde caen.

Es también exclusivo de «La mica» el desarrollo de los elementos $4,5,6,7,8$ y 10 . Sólo en esta versión el héroe acepta al animal por esposa para que salga del "martirio" en que vive. En la versión de Puebla, México (Parsons), la rana solicita del héroe (y los hermanos) que se case con ella sin preámbulos, ni razón aparente. En otras, el héroe se casa a sabiendas de que se trata de un encantamiento, o acepta como situación natural el quedarse a vivir en compañía del animal o animales que habitan la casa o palacio a que llegan. En dos versiones chilenas (Laval y Pino Saavedra \#38), los hermanos mayores of recen casamiento, sin haber visto a la poseedora de la magnífica voz que canta, pero se retractan cuando descubren que se trata de una rana. Sólo el menor mantiene la palabra. Por la misma razón se casa con la "sapa"

Poor Miller's Servantand the Cat»; «The Three Brothers», JAF, XX (1902) 91; Laval \#23, «La sapita encantada», Cuentos; Mason, «Four Mexican-Spanish Fairy Tales from Azquetlán, Jalisco: 'The Frog-Woman'», JAF, XXV (1912) 191; Elsie Clews Parsons, «The Envious Sisters», JAF, XLV (1932), 325; Rael I, \#183, «La ranita», \#184, «La ranita», \#185, «La ranita encantada», \#186, «Las garzas»; Romero, «A sapa casada», Contos, 156-158; Wheeler \#119, «Jeremillo», \#120, «La ranita encantada». Aportaciones de este estudio: Pino Saavedra I, \#37, «La mona», \#38, «La sapita encantada», \#39, «Las tres naranjas de oro», \#40, «La sapita encantada», \#41, «La ranita encantada»; Ramón y Rivera, «Los tres hijos del rey», 220; Riera Pinilla, \# 18, «La rana encantada», \#19, «La ranita encantada». 
el héroe de la versión brasileña de Silvio Romero. La versión brasileña de Câmara Cascudo es la que más se aproxima a «La mica»:

João [el héroe] seguiu na vida velha no palacio feio ao lado da Gia (...) Um ano depois, a Gia avisou que na manha seguinte seria o dia de João se presentar con a noiva (...) Eu não tenho noiva! (...) Tem, sim senhor! Sou eu! (...) João tinha vontade de fugir mas não teve coragem de pagar o bem com o mal e, com pena dea Gia ficou calado. Que cala consente ${ }^{38}$.

No sólo existe un sentimiento de compasión hacia el animal por parte del héroe en ambas versiones, sino de temor a la crítica que lógicamente traerá su matrimonio sin precedentes (elementos 9, 26 y 27). También la transformación (elemento 29) es similar en ambos:

O pobre João so maginava a mangaçao dos irmaos e do povo da rua quando fosse atravessar a povoaçao em que residiam os pais, mas ficou conformado com a vontade de Deus que lhe dera um bicho tao feio para noiva (...). O galo parou e a Gia començou a lutar para montar-se no pescoço dele. Luta que luta, sobe e desce e João, esperando, apiedade que saltou do animal e veio, rindo, ajudar a Gia a se acomodar em cima do galo. Assim que ele colocou a Gia onde ela queria ficar, ouviu-se um estrondo e passou um clarao azul, tao forte que cegava, João fechous os olhos, deslumbrado, e quando os abriu, estava deante de uma princesa bonita como una estrela ${ }^{39}$.

Es una de las versiones chilenas, el héroe también siente el peso de su situación: "Juan a veces se ponía triste y se sentía desgraciado; pero la voz encantadora de la sapita, que parecía adivinar sus penas, y

38. Câmara Cascudo, 71.

39. Câmara Cascudo, 71-72. 
sus palabras tiernas y cariñosas lo consolaban y le hacían olvidar la fealdad de la que era su mujer"40.

En «La mica», esta presenta a su esposo productos de su huerta (ayote, tacaco, canuto) en cumplimiento de los requisitos del padre (elementos 15, 17, 18 y 21). En las otras versiones los requisitos se limitan a uno o dos, y las esposas les dan una nuez o castaña u objetos como una botella desgolletada llena de agua enlodada o un saquito mugriento atado con un cordel igualmente sucio, pero sólo en «La mica» se siente el rey of endido por la aparente bajeza de los presentes que, al ser rechazados con violencia, se abren y muestran su precioso contenido (elementos $16,20,23$ ). La vaquita que se ordeña en la mesa no aparece en ninguna de las otras versiones.

El elemento 31 se presenta sólo en la versión portuguesa (Athaide). En ella, como en la costarricense, la mona (macaca), desencantada, declara tener otro reino para compartir con el esposo, por lo cual sugiere que se divida aquel entre los hermanos mayores.

No siempre es evidente la razón del encantamiento (elemento 31); en algunas versiones, ni se menciona la transformación en mujer (Mason y Wheeler \#119). La versión de Laval se aproxima más a la de Carmen Lyra en este aspecto. La mujer-bruja, que ofrece a la sapita en matrimonio, era, en realidad, una dama de la corte que mató al rey, su padre, con brujerías y la encantó a ella en venganza por haber querido echarla del reino.

«La mica» que tiene todos los elementos fundamentales del cuento-tipo, presenta un desarrollo propio en relación con las versiones consultadas. Su mayor afinidad es con las versiones de Câmara Cascudo y Laval. En «A princesa Gia», la piedad mueve al héroe, aunque en menor grado que en «La mica», pues en aquella, al aceptar el patrocinio de la ranita, acepta tácitamente el matrimonio con ella, mientras que en «La sapita encantada» (Laval), se siente obligado a mantener la palabra dada. En la brasileña, el héroe considera que lo

40. Laval, Cuentos, 185. 
sucedido se debe a la voluntad de Dios y a ella debe someterse, pero en la costarricense el príncipe se siente el único responsable, y se resigna a pagar las consecuencias de su acto. En todo momento está consciente de su error (elementos $8,9,11,12,19,26,27,29$ ), a la vez que trata de aminorar su efecto sobre los demás (elementos 12 y 25).

«Uvieta» (25-35)

Pertenece al cuento-tipo 330A (Aäme-Thompson y Hansen), «The Smith and the Devil (Death)»:

I Contract with the Devil. A smith has made a contract with the devil so that, in return for becoming a master-smith, he is to belong to the devil after a certain time.

II Receipt of a Magic Object. a) The Lord (St. Peter) visits the smith and teaches him how to be more skillful. b) The smith is granted three wishes, c) a tree that causes people to stick to it, d) a bench with the same power and, e) a knapsack that forces persons into it.

III Deceiving the Devil. a)The devil (Death) is made to stick to the bench and the tree. b) He is out into the knapsack and pounded on the anvil by the smith until he gives up his power over him.

IV Expulsion from Hell and Heaven. a) The smith goes to hell but is not admitted since the devil has lost power over him; b) he goes to heaven but is not known there and is refused admittance; c) he gets his knapsack inside and then has it pull him into it.

La versión de Carmen Lyra presenta sus elementos en la forma siguiente:

1. Un viejito vive solo y decide irse a rodar tierras.

2. Para ello compra tres bollos de pan con "el único diez" que le queda. 
3. Mientras dispone todo para la partida, tocan a la puerta sucesivamente un viejecito, una viejita y un niño de aspecto lastimero solicitando una limosna. Uvieta distribuye entre ellos sus tres bollos.

4. Al mucho andar, ya hambriento, se acerca a un riachuelo para apaciguar el hambre con agua, cuando se presenta el viejecito de la limosna, quien le explica que los limosneros eran las Tres Divinas Personas; él, San José, venía autorizado por el Señor a concederle la gracia que quisiera.

5. Después de mucho pensar, pidió un saco donde fuera a parar las cosas que él deseara. Uvieta recibe el saco.

6. Pasa una mujer con quesadillas, las que fueron a parar al saco al exclamar Uvieta: "¡Vengan esas quesadillas a mi saco!" (27). Más tarde fueron unos pececillos que nadaban en un riachuelo los que vinieron al saco.

7. Aparece luego la viejita, o sea Nuestra Señora, quien con la venia de su Hijo, se acercaba para que Uvieta le pidiera una gracia.

8. Uvieta explica que con el saco tiene para comer, pero Nuestra Señora insiste, alegando que negarse sería despreciarla, pues de San José sí había solicitado algo.

9. Uvieta, que no quiere of enderla, dice entonces que como él se llama Uvieta, le siembre en su casita "un palito de uvas" (28), del cual nadie se pueda bajar sin su permiso.

10. Más adelante, Uvieta recibe una tercera visita, esta vez, un representante del Señor, quien no se presenta en persona por no ser propio de su dignidad, pero desea también concederle una gracia a Uvieta.

11. Uvieta contesta que no quiere nada. El enviado insiste. Uvieta quiere seguir su camino, pero como insiste le encarga que le diga a Nuestro Señor que lo que desea es que lo dejen morirse a la hora que a él le dé la gana.

12. No sigue su camino sino que se devuelve para constatar si se le había concedido su segunda gracia. Así era en efecto, y se pone muy contento. 
13. Pasan los años y el Señor decide que es hora de mandar a la Muerte por Uvieta, que seguía muy entusiasmado con su palito de uvas, sin acordarse de Dios.

14. La Muerte toca a la puerta y Uvieta sin alterarse, la saluda y le pide lo espere mientras se prepara, sentándola de cara al consabido palito.

15. La Muerte se siente tentada por las uvas como Uvieta esperaba. La invita a subirse y darse gusto con ellas.

16. Naturalmente, no puede luego bajarse mientras Uvieta no se lo permita.

17. Pasan los años y la Muerte en el palo, a pesar de las embajadas de San Miguel Arcángel, San Cristóbal y San Luis Rey, entre otros.

18. La gente ya no cabe en el mundo y Dios promete no llevárselo si la deja bajar. Así lo hace Uvieta, y ella se apresura a ponerse a las órdenes del Todopoderoso.

19. Al cabode un tiempo, Nuestro Señor "que no había quedado nada cómodo con Uvieta mandó al diablo por él" (31).

20. Uvieta, a quien le sonó mal la voz del que llamaba, se asomó por el hueco de la cerradura y sospechando la verdad abrió la puerta al mismo tiempo que exclamaba: "¡Al saco el diablo!" (32). Y este se encontró en él sin poder evitarlo.

21. Sin escuchar razones, Uvieta le dio tantos garrotazos que lo hizo polvo.

22. Para que lo dejara en paz, el Señor tuvo que prometerle de nuevo que nada le pasaría, y "se vió a palitos para volver a hacer al diablo de aquel montón de polvo" (32).

23. Ya muy enojado, Nuestro Señor mandó de nuevo a la Muerte bien aleccionada, quien lo sorprendió dormido y lo depositó "a la puerta de la Gloria para que allí hicieran con él lo que les diera la gana" (33).

24. Allí lo encuentra San Pedro que al darse cuenta de quién se trata, "le hizo la cruz" (33) y absteniéndose de usar expresiones fuertes por estar en "aquel sagrado lugar" y porque "además él es un santo muy 
comedido" (33), le ordenó se fuera inmediatamente para el infierno, y así lo hizo.

25. El diablo llamó a los otros diablos para que acuñaran contra la puerta cuanto pudieran, pues "allí estaba el hombre que lo había hecho polvo" (34).

26. Uvieta pasó tres días llamando con un contraproducente "¡Ave María Purísima!"

27. Uvieta volvió a la puerta del cieloy, al explicarle a San Pedro cómo llamaba allá en la del infierno, la Virgen, que en ese momento daba de comer a unas gallinas "con pico y las patitas de oro que le habían regalado" (34), creyó que la llamaban y se asomó. Al ver a Uvieta se alegró muchísimo y lo hizo pasar adelante, sin que San Pedro se atreviera a objetar.

La diferencia fundamental entre «Uvieta» y el cuento-tipo está en la ausencia del elemento I (pacto con el diablo) de este último. En la versión de Carmen Lyra el énfasis no está en el ansia de dinero o de longevidad. Uvieta no es más que un viejito que distribuye entre unos necesitados lo único que tiene para comer (elementos 1 y 3). Estos, que resultan ser la Sagrada Familia, quieren concederle tres gracias (elementos $4,7,10)$. Uvieta se habría contentado con sólo el saco (elemento 5), que lo proveería de lo necesario, pero acaba pidiendo dos gracias más (elementos 9 y 11), a instancias de las divinas personas. En las versiones consultadas (37 en total $)^{41}$ a veces se trata de un

41. Andrade\#222, «Federico ei jugadoi»; Arellano \#395, «La tía Miseria», \#124, «Juan Soldado», \#125, «Juan Soldado»; Braga \#87, «O soldado que foi para o ceu»; Caballero, «Juan soldado», Cuentos y poesías (124); Tomás Carrasquilla, «En la diestra de Dios Padre», Seis cuentos (México: Studium, 1956) 31; Espinosa \#168, «Juan Soldado», \#169, «Juan Soldado», \#171, «La Muerte», Cuentos I; \#45, «El herrero y la Muerte», Castilla; José Manuel Espinosa \#55, «Pedro Jugadon, Spanish Folk-Tales from New Mexico (Memoirs of the Folklore Society, 1937) 127; Grimm \#81, «Merry Andrews», \#87, «The Poor and the Rich Man»; Ricardo Guiiraldes, Don Segundo Sombra (1926, México: Editorial Diana, 1961) 220-232; Mason-Espinosa \#86, «Pedro se come las pajarillas del cabro», \#87, «La muerte en el árbol», JAF, XXXV (1922) 55; «El Herrero», XXXIX(1926) 285; Ernesto Montenegro, «Miseria», Mi tio Ventura: cuentos populares de Chile (2*. ed.: Santiago de Chile: Autores chilenos, 1938) 165; Rael II, 
soldado arrogante o jugador que comparte su última soldada con Nuestro Señor, San Pedro o ambos, o un herrero, en algunos casos la miseria personificada, que da posada a unos caminantes, o no les cobra su trabajo porque parecen ser tan pobres comoél mismo, o simplemente un pícaro que viaja en compañía del Señor u otro santo y hace más picardías que caridades. (En algunas de estas versiones no es evidente el porqué de las gracias recibidas). En la versión colombiana «Por el amor de Dios», Peralta, el protagonista, comparte sus haberes con todos los necesitados del pueblo, y en la ocasión en particular, da posada a Jesús y a San Pedro. La caridad es, pues, el elemento unificador de estas versiones (excepto en algunas de las versiones de Pedro de Urdemalas, de Wheeler \# 123 y de Rael \#297 y \#300.

En cuanto a las gracias mismas, su número y especie varían. La tercera de «Uvieta» (elemento 11), esto es, morirse a voluntad, aparece sólo en dos de Nuevo Méjico: J.M. Espinoza \#55 y Rael \#274. En esta, Pedro, el protagonista, pide que se lo lleven en cuerpo y alma; en aquella, pide como Uvieta, "no morirse hasta que le dé la gana" (128). Hay también preocupación por la muerte en la colombiana de Carrasquilla. En esta, Peralta expresa el deseo de que "le manden la muerte por delante y no a traición" (35). El elemento del saco (5) es más general. Hay ligeras variantes en cuanto al objeto mismo y sus propiedades: mochila, morral, petaca, tabaquera, bolsillo; a él va, o atrae a sí todo lo que se desee, o de él no se puede salir sino a voluntad del dueño, o se cierra y se abre bajo las mismas condiciones, o está siempre lleno de dinero. Uvieta usa el saco exclusivamente como medio para conseguir qué comer (elemento 6) y para evitar que se lo lleve el diablo (elementos 20 a 23). En otras versiones se encierra en

\#274, «Pedro de Ordimalas», \#294, «Ladrio», \#295, «Mi tocayo San José», \#296, «El jugadon», \#297, «Pedro de Ordimalas», \#300, «Juan del Riñon», \#301, «Juan Soldado»; Wheeler \#123, «Los tres hermanos», \#150, \#152, \#154, \#155, «Pedro de Urdemalas», \#156 y \#157, «Juan Soldado». Versiones encontradas en el transcurso de esta investigación: Chertudi \#4, «La Miseria»; «El pollito de la Santísima Trinidad», Lecturas para un niño venezolano, 15; Pino Saavedra I, \#32, «Pedroel herrero», \#33, «El herrero y el diablo»; Adrián Recinos, «Cuentos populares de Guatemala: Pedro Ordimalas», JAF, XXXI (1918) 478. 
él al diablo o a muchos diablos juntos (Grimm \#81, Rael \#301), a la muerte (Arellano \#124, Carrasquilla, Grimm \#82), a San Pedro (Caballero), a la Gloria misma (Wheeler\#157). En «Uvieta», Nuestro Señor envía al diablo como último recurso, después de que la muerte ha farlado (elementos $12,13,14,19)$. Sólo en la versión puertorriqueña \#86 (JAF, XXV) se incluye al diablo y a la muerte, como en «Uvieta». En las treinta y seis restantes, viene uno u otro por el protagonista. También es Uvieta el único que se obstina en no dejar bajar a la Muerte del árbol a pesar de los embajadores celestiales (elemento 17).

La entrada de Uvieta al Cielo (elementos 26 y 27) no se debió a picardía (con ayuda del objeto mágico: mochila, barajas, dados, etc.), sino a la coincidencia afortunada de que la Virgen, que le estaba muy agradecida, hubiera escuchado sus " $¡ A$ ve María Purísima!". En «Por el amor de Dios» de Carrasquilla, Peralta se queda en el Cielo después de un largo proceso y un complicado veredicto dado por Santa Teresa de Jesús y Santo Tomás de Aquino. El protagonista de esa versión es la "humildá" y la "caridá" mismas, mientras que en Arellano \#95, Andrade \#222, Chertudi, Güiraldes, Montenegro, Espinosa, Castilla \#45 es la miseria misma. Tanto Miseria como el Pedro jugador de la versión de Nuevo Méjico (J. M. Espinoza \#55) están aún en el mundo porque fueron rechazados por el Cielo, el Infiemo y el Purgatorio. En Grimm \#82, el alma del jugador se divide en trocitos que van a parar a las almas de los jugadores que aún viven.

Por la astucia de Uvieta y la doble visita de la muerte, además de la del diablo, la versión de Carmen Lyra presenta puntos de contacto con el mito griego de Sísifo ${ }^{42}$. A este personaje se le atribuía ya en tiempos de Homero, la paternidad de Ulises a causa de su gran astucia. Según el mito, Sísifo había provocado la ira de Zeus, quien mandó a Tánatos (la muerte) para que se lo llevara. Sísifo, con engaños, logra retenerlo prisionero. Zeus manda entonces al temido y odiado Ares,

42. «Bellerophon and the Heroes of Corinth: Sisyphus,» Larousse Encyclopedia of Mythology (New York: Prometheus Press, 1959) 202. 
dios de la guerra. Sísifo no tiene más remedio que dejar en libertad a Tánatos y acompañar a Ares. Antes de partir, le encarga a su mujer que no le haga pompas fúnebres, confiando en que ella le desobedecería, como efectivamente sucede. Sísifo solicita de Hades que le permita regresar por un momento a la tierra para castigarla. Hades se lo concede. Una vez en este mundo, Sísifo rehúsa volver al otro. Zeus manda esta vez al gentil Hermes, encargado también de conducir almas al mundo de los muertos, y Sísifo se somete definitivamente. Es castigado a empujar cuesta arriba una enorme roca por toda la eternidad.

El cuento «Uvieta» de Carmen Lyra no representa una alegoría, ni encierra personificación ni moraleja. Su héroe no hace pactos con el diablo ni es un pícaro que logra entrar al cielo por medio de trucos, sino un hombre como todos, cuyo único derecho a la otra vida es un pequeño acto de caridad, y que como en «Los Milagros» de Berceo, gana la Gloria en el último momento gracias a la intervención de Nuestra Señora.

\section{Cuentos acumulativos}

Pertenecen a la categoría de cuentos acumulativos o de fórmula aquellos en que se repiten palabras, rimas, acumulaciones de incidentes lógicos o ilógicos, según fórmulas fijas o determinadas. Archer Taylor estudió estos cuentos e hizo cuatro clasi ficaciones de ellos ${ }^{43}$. Una de ellas es la de los cuentos encadenados, al cual pertenece «La Cucarachita Mandinga». Aurelio Espinosa define los cuentos encadenados como cuentos de niños y para niños que, generalmente, se cuentan en tono recitativo, y a veces hasta se cantan. Algunos han creído ver en ellos vestigios ritualistas, pero Espinosa pone en duda esta opinión ${ }^{44}$.

43. Archer Taylor, «Formelmärchen», JAF, XLVI (1933), 77-88.

44. Aurelio M. Espinosa, Cuentos, III (1947) 441-444. 
«La Cucarachita Mandinga» (89-97)

Aäme-Thompson y Boggs lo clasifican como cuento-tipo 2023 y Hansen como * 2023. Este último lo describe así:

Little ant finds a penny, buys new clothes with it, and sits in her doorway. Various animals pass by and propose marriage. She asks what they do at night. Every one replies with its characteristic sound, but none pleases her but the little quiet mouse, whom she marries. She leaves him to tend the stew, and he falls in and drowns. She weeps and, on leaming the reason, bird cuts off its beak, dove cuts its tail, etc.

El cuento de Tía Panchita, desmembrado en elementos, es como sigue:

1. La Cucarachita Mandinga al barrer las gradas de su casa se encuentra un "cinco" (89).

2. Empieza a deliberar: ¿Si lo gasta en colorete, aretes, sombrero? No, porque no le lucen. Se decide por cintas.

3. Se baña, se empolva, se peina de pelo suelto y lazo en la cabeza. Se va a la calle de la Estación y busca asiento.

4. Desfilan animales que, al verla, se quieren casar con ella: un toro, un perro, un gallo. Ella les pregunta qué ruido hacen de noche y los rechaza porque su ruido la asustaría.

5. Acepta a Ratón Pérez porque le gusta su "¡I, i, ii ...!" (91).

6. Al siguiente día de la boda, la Cucarachita pone al fuego una olla de arroz con leche. Encarga a Ratón Pérez que le vea la olla pero sin golosearla, y se va por agua.

7. Ratón Pérez va a la olla, mete una pata, luegootra, peroel arroz está muy caliente. Acerca un banco, se sube y mira. Mete las narices para respirar el agradable olor y cae dentro.

8. Cucarachita tiene luego que traer a un carpintero para que abra la puerta. 
9. Se pone como loca al verlo "bailando en la olla" (93). Lo coloca en un ataúd y se sienta a llorar a la puerta de su casa.

10. Pasan: una palomita que en señal de duelo se corta una alita, un palomar que "se quita el alar" (93), la reina que se corta una piema, el rey que se quita la corona, el ríoque se "tira a secar" (96), unas negras que quiebran sus cántaros y un viejito que se deguiella.

11. Cucarachita le hace un entierro rumboso con "violines y violones" (97).

Espinosa, en su estudio de los cuentos de fórmula hispánica, divide las sesenta y cuatro versiones (que incluyen diez y siete de un tema semejante: el cuento en verso que relata las bodas del piojo y la pulga, terminado de manera semejante al de la cucaracha) en tres tipos diferentes, siendo el tipo I el fundamental hispánico: la cucaracha que se casó con el ratoncito, la muerte de este y el extraordinario duelo. Cita al de Carmen Lyra entre los de este grupo ${ }^{45}$.

De las versiones consultadas ${ }^{46}$, omiten el duelo las dos mexicanas (Robe), la ecuatoriana (Carvalho), en la cual la cucarachita descubre al ratoncito muerto en "la colada" 47 y "llorando, llorando, se comió al ratoncito" (108) y la chilena (Pino Saavedra III).

45. Espinosa, Cuentos III (1947) 446.

46. Arellano \#99 a, b, c, «La Cucarachita Martina»; Athaide O. I, «A Carochinha», 183; Robe \#142, «El Ratón Pérez», \#144, «La hormiguita y el ratón»; Fernán Caballero, «La hormiguita» Cuentos, adivinanzas y refranes populares, 5-7; Carvalho, «La Cucarachita Mandinga», Cuentos, 105; Adolpho Coelho, «Historia da Carochinha», 1; Espinosa \#271, \#272, \#273, «La hormiguita», \#274, «La mariposita», Cuentos I, 613-622; Mason-Espinosa \#24, «La Cucarachita Martínez y el Ratoncito Pérez», \#27, «La hormiga», JAF, XL (1927) 338-341; Vicente T. Mendoza \#32, «El piojo y la pulga» (Andalucía) 743; \#33 a \#37, «El casamiento del piojo y la pulga» (versiones de Zacatecas, Veracruz, México, Querétaro y Tampico), El romancero español, 744-748; Mendoza \#176 a \#178, «El casamiento del piojo y la pulga», Lírica infantil de México (El Colegio de México, 1951) 138-139; Elsie Clews Parsons, «Sir John Big Rat and Susana» (3 versiones), JAF, XXXII (1919) 37; Pino S. \# 224, «La hormiguita y Ratón Pérez», III (1963) 158-159; Rael II, \#393, «La hormiguita y el Ratón Peles». Aportaciones de este estudio: John Brooks, «Spanish American Folklore in Arizona: la hormiguita gime y llora», University of Arizona Bulletin, № 9, XVI, № 1 (1945) 19-21; Ildefonso Paredes Valdés, «La ratonera y el ratón», Folklore de las Américas (ed. F. Coluccio, Buenos Aires: El Ateneo, 1949) 424.

47. "Colada: comida de harina de maíz, cebada o trigo batida en agua y hervida", Paulo de Carralho Neto, Diccionario del folklore ecuatoriano (Quito: Casa de la Cultura Ecuatoriana, 1964) 133. 
Los elementos de la versión de Tía Panchita son esencialmente los mismos del cuento-tipo y concuerdan con los dados por Espinosa en su estudio (445-450). Las variaciones se encuentran en los diferentes objetos que la cucarachita piensa comprar (elemento 2), las actitudes de coquetería (elemento 3), los animales-pretendientes (elemento 4), el contenido de la olla en que cae el ratón (elemento 6) y los personajes que toman parte en el duelo (elemento 11).

La cucarachita de Carmen Lyra no se decide por el colorete, porque piensa que no le luce, detalle muy a propósito, ya que no se vería bien con el color oscuro de la cucaracha. De las treinta y tres versiones consultadas, una de Puerto Rico (Mason-Espinosa \#25) y la ecuatoriana (Carvalho), la cucaracha u hormiga escoge también una cinta. En esta última es "para hacerse un peinado bonito y buscar un novio con quien casarse" (105). En la española de Espinosa también compra cintas, además de otras prendas de vestir. El arroz con leche de la versión que nos concieme, cuyo vaho "olía a gloria" (92) y tienta a Ratoncito Pérez provocando la tragedia, es típico del país, "con queso en polvo y astillitas de canela" (92). Entre los personajes que desfilan por Tía Panchita ninguno es exótico, pero en el desfile sí participan personajes ajenos al medio como la reina que se corta una pierna, el rey que se quita la corona (elemento 10). Ambos aparecen en casi todas las versiones. Ejecutan actos tan extravagantes como: el rey quitarse los pantalones y echar a correr en calzoncillos (Espinosa \#274), la reina vestirse de amarillo y el rey cortarle una oreja a su caballo (Rael II, \#393). En la versión de Athaide la reina dice: "—Já que o rei cortou as barbas, / Assento o meu c ... nas brazas" (184), mientras en la otra portuguesa (Coelho), la reina dice: "Pois eu que sou rainha / Andarei em fralda pela cozinha". A lo que el rey dice: "E eu vou arrastrar o c ... / Pelas brazas" (5). Sólo tres versiones incluyen personajes negros, además de Tía Panchita: la nuevomexicana(Rael), la de Arizona (Brooks) y la uruguaya (Paredes Valdés). Todos ellos quiebran su cántaro en señal de duelo. Únicamente en Tía Panchita termina el duelo con el viejito que se deguiella. También es exclusivo de esta variante el elemento del entierro (9 y 11): 
La Cucarachita quiso que fuera bien rumboso e hizo venir músicos que iban detrás del ataúd tocando. Los violines y los violones decían: - iPor jartón, por jartón,, por jartón/ se cayó entre la olla! (97).

Es como si con este toque humorístico, Carmen Lyra quisiera aminorar el efecto que pudiera causar el final violento: el vie jito que se degüella, y hacer de la tragedia de Ratoncito Pérez y la Cucarachita Mandinga, una comedia.

La discusión anterior demuestra que el cuento de la cucaracha o la hormiga que se casa con un ratón existe en la tradición de España, Portugal, Brasil, Argentina, Chile, Ecuador, Nuevo México, Arizona, entre otros, de modo que no nos sorprende que exista en Costa Rica también. De hecho, me fue posible recoger dos versiones imperfectas del cuento en verso del casamiento del piojo y la pulga (tipo III), según la clasif icación de Espinosa ${ }^{48}$ y semejantes a las editadas por Mendoza que se citan a continuación:

El piojo y la pulga

se van a casar

y no se han casado

por falta de maíz

Tiro, lo tiro,

liro, liro, liro

liro, liro, lá.

El piojo y la pulga

se van a casar

y no se han casado

por falta 'e madrina.
Salta la gallina que se desatina, traigan unas naguas yo seré madrina.

Tiro, etc.

El piojo y la pulga se van a casar y no se han casado por falta 'e padrino.

Tiro, etc.

48. Espinosa, Cuentos III, 448. 
Tiro, etc.

Responde el ratón desde su ratonal, amarren al gato, voy a apadrinar

Tiro, etc.
Se acabó la boda hubo mucho vino se soltó al gatito, se comió al padrino ${ }^{49}$

II

La pulga y el piojo

se van a casar, por falta de cura

se van a quedar.

Responde tío Zorro por ser más honrado, síganse las bodas, yo caso de fiado.

Responde la chancha con tamaña horqueta, síganse las bodas, yo sirvo 'e peineta

A pesar de lo incompleto de esta segunda versión, se evidencia la autenticidad popular en el uso de palabras tales como "chancha" y "horqueta", esta última definida por Gagini como: "Triángulo de

49. Versión dada en San José, Costa Rica, el verano de 1970 por Gerardo Lobo.

50. La informante, señora Olga Sancho, San José, Costa Rica, verano de 1970, no pudo recordar sino lo arriba citado. 
madera que se pone en el cuello de las vacas rompedoras, terneros y cerdos, para que no pasen por los portillos de los setos o cercas" ${ }^{\text {I1 }}$. La ironía del segundo verso, "por ser más honrado", refiriéndose al zorro, parece también delatar su origen popular, o más bien dicho, campesino (al campesino costarricense se le atribuye un humor agudo semejante).

Si existe la tradición de la cucarachita o la hormiguita en otros países, y efectivamente existió o existe en Costa Rica, la versión de «La Cucarachita Mandinga» de Carmen Lyra no tiene necesariamente que ser adaptación de la de Fernán Caballero como se ha sugerido ${ }^{52}$, aunque Lyra la conocía bien, pues a ella se refiere en su introducción a los cuentos: "Recuerdo el cuento de «La Cucarachita Mandinga» («La hormiguita» de Fernán Caballero, vaciado en molde quizá americano, quizá tico solamente), que no nos cansábamos de escuchar" ${ }^{\text {53. }}$.

El hecho de que la palabra "mandinga" forma parte integrante del cuento de Carmen Lyra, y no del de Fernán Caballero, contribuye a reforzar la paternidad de él por parte de la primera, quien ef ectivamente debió transcribirlo al papel de fuentes vivas y no literarias. Esto parece estar apoyado por otro pequeño detalle: el uso de las palabras nada castizas "chutás" (asustás) y "luche" (luce) (90) que aparecen en el diálogo de la cucaracha con los animales y en su monólogo cuando vacila en cuanto a la manera de gastar el "cinco" encontrado. Carmen Lyra, que escribe para costarricenses, se siente obligada a aclararlas con notas al pie de la página. Si se tomaran como palabras del habla infantil, la anotación sobraría, pues serían reconocida por grandes y chicos.

51. Gagini, Diccionario de costarriqueñismos, 159.

52. Margarita Castro Rawson, El costumbrismo en Costa Rica (San José: Editorial Costa Rica, 1966) 210 , en nota al pie de la página, asume que la versión de Carmen Lyra es adaptación de la de Fernán Caballero.

53. Lyra, «Introducción a Cuentos de mi tía Panchita», Lecturas, $n^{\circ} 1$ (30de septiembre de 1918) 4-5. También pp. 13-14 de la cuarta edición. 